Pediat. Res. 2: 332-351 (1968)

\title{
Alterations in Renal Cortical Blood Flow in Infants and Children with Urinary Tract Infections
}

\author{
P.L. Calgagno ${ }^{[30]}$, J.B. D’Albora, L.U.Tina, Z.L. Papadopoulou, P.F. Deasy and C.E. Hollerman \\ Department of Pediatrics, Georgetown University School of Medicine, \\ and the Children's Hospital of the District of Columbia, Washington, D.C., USA
}

Extract

The present studies were designed to elucidate renal functional changes in infants and children with urinary tract infections. Twenty-three infants and children ranging in age from 4 months to $136 / 12$ years with urinary tract infections were studied. Four children ranging in age from 2 to $6^{10} / 12$ years without documented urinary tract infections served as controls. Inulin clearances $\left(\mathrm{C}_{\mathrm{I}}\right)$ were utilized for measurement of glomerular filtration rate. Renal plasma flow and tubular maximum excretory capacity were ascertained by the intravenous administration of para-aminohippurate (PAH). Second determinations performed in eight patients and a third determination in one patient provided longitudinal follow-up. Renal plasma flow measurements were low in 4 of 6 infants and in 6 of 17 children on initial testing; these decreased values were associated with normal glomerular filtration rates except in 3 subjects. In the 4 patients without documented urinary tract infections, $\mathrm{C}_{\mathrm{PAH}}$ values were within the normal range. $\mathrm{C}_{\mathrm{PAH}}$ values obtained initially in all subjects were compared on a surface area basis to those characteristic of normal children. Of the 27 experimental points, 21 were below the line representing the normal average $\mathrm{C}_{\mathrm{PAH}}$ for children. In this small series, only one of three infants failed to recover this function at the time of repeat testing. The recovery rate was less in the children studied. The data indicate that a decrease in renal plasma flow occurs prior to significant alterations in the other renal functional parameters measured.

Twenty-two subjects were tested for both $\mathrm{C}_{\mathrm{PAH}}$ and $\mathrm{Tm}_{\mathrm{PAH}}$. The ratio $\left(\mathrm{C}_{\mathrm{PAH}} / \mathrm{Tm}_{\mathrm{PAH}}\right)$ was lower in all three groups than the reported normal value of 7.7. In those patients demonstrating an initially reduced value, 13 of 16 showed normal $\mathrm{C}_{\mathrm{PAH}}$ values. These findings could represent renal ischemia of proximal tubular tissue.

The persistence of renal vascular changes in the face of absent clinical and/or laboratory evidence of urinary tract infections emphasizes the need for caution in identifying the prognosis of children with pyelonephritis and the need for careful long-term evaluation.

\section{Speculation}

Although it has been well documented that the renal medulla is the primary site of involvement in pyelonephritis, the current data suggest that the post-glomerular capillaries and tubular structures in the renal cortex are also early sites of involvement in infants and children. A question raised by the study is the relation of reduced renal plasma flow measurements to the natural history and pathogenesis of recurrent pyelonephritis. It is suggested that agents promoting a change toward normal renal circulation may reverse the pathologic process. 


\section{Introduction}

Acute pyelonephritis is a relatively common illness in children. Unsuspected urinary tract infections occur in $1.1 \%$ in young girls and $0.03 \%$ in young boys [18]. The recurrence rate in patients with overt disease following therapy varies from 32 to $60 \%[8,17,20]$. Notwithstanding the relative frequency of pyelonephritis, data on renal functional measurements in children with acute urinary tract infections are sparse.

The presence of diminution in renal concentrating ability has been reported in children with acute nonobstructive urinary tract infections [28]. The present studies were designed to elucidate changes in kidney function in children with urinary tract infections. The majority of the patients studied had had recurrent urinary tract infections; the remainder had had either a single episode of infection or persistent infection. The latter two groups comprised one-fourth and one-twelfth, respectively, of the patients investigated. The data indicate that a decrease in renal plasma flow occurs prior to significant alterations in the other renal functional parameters measured.

\section{Material}

Twenty-three infants and children with urinary tract infections who were from 4 months to $13 \% / 12$ years of age were studied. Of these patients, one (patient No. 7) with untreated acute infection was studied within three weeks of onset; six (patients Nos. 1-4, 8, 9) with no recurrences had received chemotherapy for several months prior to study; and sixteen (patients Nos. 5, 6, 10-23) with recurrent urinary tract infections had received prolonged chemotherapy prior to investigation. Four patients (Nos.24-27) without documented urinary tract infections who were 2 to $2^{10} / 12$ years of age were also studied.

Of the 23 patients with urinary tract infections, five were males; in three of these, the infections were detected during the newborn period. The urologic abnormalities found in the males were as follows: posterior urethral valves in two; bladder neck contracture and meatal stenosis in one; and a post-traumatic neurogenic bladder in one. The urologic findings demonstrable in females were: bladder neck obstructions in seven; meatal stenosis in two, combined bladder neck contractures and meatal stenosis in six; a complex of bladder neck contracture, meatal stenosis and urethral stenosis in one; and a double collecting system in one. In all, obstructive lesions of the urinary tract were found in 21 of the 23 patients.

The urologic findings in the four patients without documented urinary tract infection were as follows: bladder neck contracture in one; urethritis in one; megacystis in one; and no demonstrable abnormality in one.

Body weights for the 27 patients ranged from 5.5 to $45.4 \mathrm{~kg}$; estimations of surface area made on the basis of height and weight were between 0.32 and $1.62 \mathrm{~m}^{2}$.

A diagnosis of urinary tract infection was made when, in two or more consecutive urine cultures, the same organism was isolated and quantitative colony counts were at least $10^{5}$ per milliliter of urine.

Microscopic examination of a portion of the urine collected for culture usually revealed more than 50 $\mathrm{WBC} / \mathrm{mm}^{3}$ in the unspun specimen or $5 \mathrm{WBC} / \mathrm{HPF}$ in the centrifuged sediment.

At the onset of their disease, approximately one-half of the patients demonstrated the usual symptomatology referrable to the urinary tract; the remainder had either vague general complaints or were asymptomatic. The same pattern of symptomatology was present at the time renal function tests were conducted. The initial episode was usually treated with oral administration of sulfisoxazole at a dosage level of $120 \mathrm{mg} / \mathrm{kg} /$ day for six weeks. After discontinuation of the drug, the therapeutic regimen was considered successful if the following conditions were fulfilled: three negative urine cultures taken at biweekly intervals; clearing of the urinary sediment; and disappearance of symptomatology. Following the initial infection, the patients were reevaluated monthly. Recurrences or relapses were treated with an appropriate antimicrobial agent, usually sulfisoxazole or nitrofurantoin, for a period of six months or longer.

Renal functional measurements were determined in subjects in whom bacteriuria had been present for as short a period as two weeks and in patients with intermittent bacteriuria for a period as long as $3 \% / 12$ years. Specific antimicrobial therapy had been given before measurements of renal function were made, except in patients Nos.7, 24, and 27. A second series of determinations were obtained in eight patients, Nos. 1, 2, 5, 6, 16, 17, 18, and 22, at intervals of 5 to 29 months. A third series of studies was completed in patient No. 2 to provide further long-term evaluation.

\section{Methods}

Inulin clearance $\left(\mathrm{C}_{\mathrm{I}}\right)$ was used to measure glomerular filtration rate. Renal plasma flow and tubular maximum excretory capacity were ascertained by the intravenous administration of para-aminohippurate (PAH). During the first equilibration period, the infusion rate was calculated to produce plasma values greater than $25 \mathrm{mg} \%$ for inulin and 1 to $3 \mathrm{mg} \%$ for PAH. The techniques employed for sedation of the patients and collec- 
tion of samples during each period were essentially the same as those previously reported [10]. Following the three clearance periods of 10 to 15 minutes, $\mathrm{PAH}$ administration was increased to maintain plasma values above $40 \mathrm{mg} / 100 \mathrm{ml}$; three additional collection periods were then obtained for determination of the tubular maximum for PAH transport (TmPAH).

Inulin was determined chemically by the method of HubBard and Loomis [15] and para-aminohippurate by the method of SMith and FinkeLstein [25]. Solutions of inulin and para-aminohippurate with known concentrations were utilized for construction of a calibration curve for each set of determinations. All determinations, standard and unknown, were assayed in duplicate.

The clearance protocol in patient No. 17 is shown in table I. The steady state plasma values, the consistency of urine flow, and the agreement between values for each collection period are representative of the data acquired in this study. The significant decrease observed in glomerular filtration rate during TmPAH studies is characteristic [19].

The 100-percent value for glomerular filtration rate was $117 \mathrm{ml} / \mathrm{min} / 1.73 \mathrm{~m}^{2}$ for girls and $131 \mathrm{ml} / \mathrm{min} /$ $1.73 \mathrm{~m}^{2}$ for boys $[9,22,24,27]$, with a standard deviation of \pm 15.6 for girls and \pm 21.5 for boys.

The 100-percent value used for para-aminohippurate clearance $\left(\mathrm{C}_{\text {PAH }}\right.$ ) was $594 \mathrm{ml} / \mathrm{min} / 1.73 \mathrm{~m}^{2}$ for girls and $697 \mathrm{ml} / \mathrm{min} / 1.73 \mathrm{~m}^{2}$ for boys [9, 22, 24, 27], with a standard deviation of \pm 102.4 for girls and \pm 135.9 for boys.
The 100-percent value utilized for the tubular maximum excretory capacity for para-aminohippurate (TmPAH) was $77.5 \mathrm{mg} / \mathrm{min} / 1.73 \mathrm{~m}^{2}$ for both sexes with a standard deviation of $\pm 12.9[9,22,24,27]$.

The mean value for the relation of $\mathrm{C}_{\mathrm{PAH}}$ to $\mathrm{TmPAH}$ was 7.7 for normal children [9, 22, 24, 27].

\section{Results}

Pertinent data on clinical course, urologic findings, renal function, urinary sediment, and bacteriologic cultures are presented in tables II, III, and IV. Abbreviated chronological case histories may be found in tabulated form in an appendix.

\section{Infants}

Data on the six infants studied are presented in table II. The glomerular filtration rates were within one standard deviation of the normal with the exception of that of patient No.2, in whom the inulin clearance remained low even at the age of $26 / 12$ years but was normal at the age of $3 \frac{3}{12}$ years. The existence of hydronephrosis did not appear to influence the inulin clearances in these patients.

Renal plasma flow was decreased by greater than one standard deviation in patient No. 2 and in three others. When studies were repeated, $\mathrm{C}_{\mathrm{PAH}}$ showed no

Table I. Clearance protocol-patient No. 17

\begin{tabular}{|c|c|c|c|c|c|c|c|}
\hline Period & $\begin{array}{l}\text { Time } \\
\text { (minutes) }\end{array}$ & $\begin{array}{l}{ }^{1} \mathrm{P}_{\text {inulin }} \\
\mathrm{mg} / \mathrm{ml}\end{array}$ & $\begin{array}{l}{ }^{x} \mathrm{P}_{\mathrm{PAH}} \\
\mathrm{mg} / \mathrm{ml}\end{array}$ & $\begin{array}{l}\text { Urine flow } \\
\mathrm{ml} / \mathrm{min}\end{array}$ & $\begin{array}{l}\mathrm{C}_{\text {inulin }} \\
\mathrm{ml} / \mathrm{min} / 1 .\end{array}$ & $\begin{array}{l}\mathrm{C}_{\mathrm{PAH}} \\
73 \mathrm{~m}^{2}\end{array}$ & $\begin{array}{l}\mathrm{TmPAH} \\
\mathrm{mg} / \mathrm{min} / \\
1.73 \mathrm{~m}^{2}\end{array}$ \\
\hline 0 & 0 & 0 & 0 & 0 & 0 & 0 & 0 \\
\hline \multicolumn{8}{|c|}{ Equilibration No. 165} \\
\hline 1 & 15 & 0.26 & 0.013 & 1.2 & 102 & 466 & \\
\hline 2 & 10 & 0.26 & 0.012 & 1.6 & 111 & 504 & \\
\hline 3 & 10 & 0.26 & 0.012 & 1.6 & 105 & 467 & \\
\hline \multicolumn{8}{|c|}{ Equilibration No.2 60} \\
\hline 4 & 12 & 0.43 & 0.82 & 2.5 & 89 & 202 & 105 \\
\hline 5 & 8 & 0.45 & 0.84 & 2.5 & 90 & 200 & 105 \\
\hline 6 & 10 & 0.47 & 0.87 & 2.4 & 82 & 186 & 102 \\
\hline
\end{tabular}

1 The plasma values given in periods $1-6$ are concentrations of inulin and PAH at the mid-point of each period. 
Alterations in renal cortical blood flow in infants and children with urinary tract infections 335

improvement in patient No.5, a rise to normal levels in patients Nos. 1 and 2, and no change from normal values in patient No. 6. Bacteriuria of greater than $10^{5}$ colonies/ml of urine was associated with both normal and diminished renal plasma flow. Vesicoureteral reflux, though present in all infants having a decreased renal plasma flow, appeared to have no influence on the glomerular filtration rate.

TmPAH values in the infants tested were all within one standard deviation of normal with the exception of those in the initial study of patient No. 5 .

The relation of $\mathrm{G}_{\mathrm{PAH}}$ to TmPAH was determined in five of the infants. The mean value, 6.4 , is diminished in comparison with the normal mean, 7.7.

\section{Children}

Renal function data in the 17 children with documented urinary tract infections are listed in table III. Glomerular filtration rates were within one standard deviation of normal values except in patients Nos. 15 and 21. These latter patients did not have the serious obstructive uropathy demonstrated in the patients with normal renal clearance values, for example, patient No.8. Renal plasma flow more than one standard deviation below normal was demonstrated on initial testing in six patients (Nos. 7, 9, 13, 15, 17, and 23); in three others (Nos.14, 18, and 21), the values were borderline. Patient No. 7 was the only subject studied within three weeks of the onset of urinary tract infection. Eight patients had normal values for renal plasma flow. Determinations were repeated on four patients $15 / 12$ to $24 / 12$ years after the initial studies. Patient No. 17 had a rise to normal values; in patients Nos. 16, 18, and 22 , the values fell from normal or borderline normal levels to those significantly below normal. Bacteriuria of $10^{5}$ colonies $/ \mathrm{ml}$ of urine at the time of the studies was associated with both normal and decreased values for $\mathrm{C}_{\mathrm{PAH}}$.

TmPAH was determined in 13 of the 17 subjects with the exception of patient No.15; values within \pm one standard deviation were found in all. In eight patients, values greater than one standard deviation above the mean were present upon initial or subsequent testing.

The relation of $\mathrm{C}_{\mathrm{PAH}}$ to $\mathrm{TmPAH}$ was determined in 13 patients. The mean value was 5.3 , compared to the normal of 7.7.

Four children without documented urinary tract infection but with possible urinary tract obstruction were also studied. Renal function data on these patients are recorded in table IV. All subjects had normal values for glomerular filtration rate and renal plasma flow. In three children, TmPAH was greater than one standard deviation above normal; the mean ratio of $\mathrm{C}_{\mathrm{PAH}} / \mathrm{TmPAH}$ was 5.1 .

\section{Discussion}

The use of PAH for measurement of renal plasma flow is predicated on the assumption that greater than $90 \%$ of $\mathrm{PAH}$ is removed in one circulation through the kidney. Studies [10] have shown that the extraction of $\mathrm{PAH}$ by the kidney of the normal newborn is considerably less than that of the adult. During the first half year of life, $\mathrm{PAH}$ extraction $\left(\mathrm{E}_{\mathrm{PAH}}\right)$ increases and reaches adult values by six months of age. In the present study, all but one of the patients were six months of age or older. PAH clearance may therefore be used as a reasonable approximation of true renal plasma flow, provided the $\mathrm{E}_{\mathrm{PAH}}$ is complete in children with urinary tract infections. Such data are not yet available. Renal plasma flow measurements and $\mathrm{E}_{\mathrm{PAH}}$ have been found to decrease in adults with chronic pyelonephritis; this change is thought to be due to destruction of renal parenchyma $[4,21]$.

When urine flow is very low, storage of PAH in the kidney may occur $[1,2]$. In the present study, the urine volumes achieved were sufficient to prevent this (see table I). Storage of PAH in erythrocytes in children is not a factor in these studies since diffusion rates of red cells to plasma studied previously in three subjects between 2 weeks and $56 / 12$ years of age failed to change the renal extraction of para-aminohippurate $\left(\mathrm{E}_{\mathrm{PAH}}\right)$ [10]. Determination of concentrations of $\mathrm{PAH}$ in the lymph of dogs was very close to those present in the renal artery and vein [7]. This finding supports the conclusion that the presence of $\mathrm{PAH}$ in renal lymph could not be a cause of significant error in renal plasma flow measurements [24]. Nevertheless, studies in experimental pyelonephritis are needed to further clarify this question.

Back pressure from obstruction of urine flow sufficient to result in renal intrapelvic pressures as high as $73 \mathrm{~mm} \mathrm{Hg}$ has been shown to reduce renal plasma flow [16]. While, in the dog, ligation of one ureter reduced renal blood flow by $40 \%$ on the obstructed side, the contralateral side demonstrated a compensatory increase in renal plasma flow so that the total flow measurements were increased [23]. None of the patients in this study demonstrated a degree of obstructive uropathy sufficient to explain the low $\mathrm{PAH}$ clearances observed.

Renal plasma flow measurements were low in 4 of 6 infants and in 6 of 17 children at the time of initial testing; these decreased values were associated with normal glomerular filtration rates except in three subjects. In the four patients without documented urinary tract infections, $\mathrm{C}_{\mathrm{PAH}}$ was within the normal range. Figure 1 shows that the initial values for $\mathrm{C}_{\mathrm{PAH}}$ obtained in all subjects was similar to known normal childhood values. It will be noted that 13 of 23 values were one 
Table II. Clinical and renal function. Data on infants with urinary tract infections

\begin{tabular}{|c|c|c|c|c|c|c|c|c|c|c|c|}
\hline \multirow{2}{*}{ 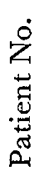 } & \multirow[b]{2}{*}{ 茏 } & \multirow{2}{*}{ 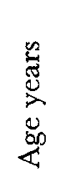 } & \multirow{2}{*}{ 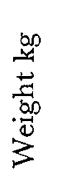 } & \multirow{2}{*}{ 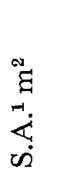 } & \multirow[b]{2}{*}{ 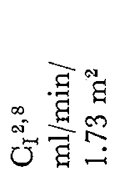 } & \multirow{2}{*}{ 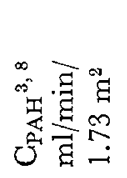 } & \multirow{2}{*}{ 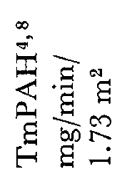 } & \multirow{2}{*}{ 焉 } & \multicolumn{3}{|r|}{ At time } \\
\hline & & & & & & & & & $\begin{array}{l}\text { On } \\
\mathrm{Rx}\end{array}$ & Symptoms & $\begin{array}{l}\text { Urine } \\
\text { sediment }\end{array}$ \\
\hline \multirow[t]{2}{*}{1} & $F$ & $4 / 12$ & 5.5 & 0.32 & $\begin{array}{l}102 \\
(87 \%)\end{array}$ & $\begin{array}{l}323 \\
(54 \%)\end{array}$ & & & + & $\begin{array}{l}\text { failure to thrive, } \\
\text { persistent } \\
\text { bacteriuria }\end{array}$ & negative \\
\hline & & $11 / 12$ & 7.4 & 0.37 & $\begin{array}{l}133 \\
(114 \%)\end{array}$ & $\begin{array}{l}606 \\
(102 \%)\end{array}$ & $\begin{array}{l}130 \\
(167 \%)\end{array}$ & 4.9 & + & none & $\begin{array}{l}20-30 \\
\mathrm{WBC}^{2} \\
\mathrm{HPF}^{6}\end{array}$ \\
\hline \multirow[t]{3}{*}{2} & $\mathrm{M}$ & $6 / 12$ & 9.4 & 0.41 & $\begin{array}{l}64 \\
(49 \%)\end{array}$ & $\begin{array}{l}259 \\
(37 \%)\end{array}$ & & & + & none & $\begin{array}{l}20-30 \\
\text { WBC/ } \\
\text { HPF }\end{array}$ \\
\hline & & $2^{1} / 12$ & 13.0 & 0.54 & $\begin{array}{l}90 \\
(69 \%)\end{array}$ & $\begin{array}{l}372 \\
(53 \%)\end{array}$ & & & - & none & negative \\
\hline & & $3^{3} / 12$ & 15.0 & 0.60 & $\begin{array}{l}152 \\
(115 \%)\end{array}$ & $\begin{array}{l}615 \\
(88 \%)\end{array}$ & & & - & none & negative \\
\hline 3 & $\mathrm{M}$ & $6 / 12$ & 5.6 & 0.30 & $\begin{array}{l}160 \\
(122 \%)\end{array}$ & $\begin{array}{l}697 \\
(100 \%)\end{array}$ & $\begin{array}{l}82 \\
(106 \%)\end{array}$ & 8.4 & + & $\begin{array}{l}\text { failure to thrive } \\
\text { dribbling on } \\
\text { urination }\end{array}$ & negative \\
\hline 4 & $\mathrm{M}$ & $6 / 12$ & 10.0 & 0.42 & $\begin{array}{l}154 \\
(118 \%)\end{array}$ & $\begin{array}{l}421 \\
(60 \%)\end{array}$ & $\begin{array}{l}89 \\
(148 \%)\end{array}$ & 4.7 & + & negative & negative \\
\hline \multirow[t]{2}{*}{5} & $\mathrm{~F}$ & $8 / 12$ & 7.2 & 0.41 & $\begin{array}{l}162 \\
(138 \%)\end{array}$ & $\begin{array}{l}422 \\
(71 \%)\end{array}$ & $\begin{array}{l}55 \\
(71 \%)\end{array}$ & 7.4 & + & negative & negative \\
\hline & & $13 / 12$ & 10.0 & 0.43 & $\begin{array}{l}125 \\
(107 \%)\end{array}$ & $\begin{array}{l}387 \\
(65 \%)\end{array}$ & $\begin{array}{l}88 \\
(135 \%)\end{array}$ & 4.4 & - & negative & negative \\
\hline \multirow[t]{2}{*}{6} & $\mathrm{~F}$ & 2 & 10.9 & 0.48 & $\begin{array}{l}212 \\
(181 \%)\end{array}$ & $\begin{array}{l}848 \\
(143 \%)\end{array}$ & $\begin{array}{l}121 \\
(156 \%)\end{array}$ & 7.0 & - & failure to thrive & $\begin{array}{l}10-20 \\
\text { WBC/ } \\
\text { HPF }\end{array}$ \\
\hline & & $25 / 12$ & 11.6 & 0.55 & $\begin{array}{l}102 \\
(87 \%)\end{array}$ & $\begin{array}{l}876 \\
(148 \%)\end{array}$ & $\begin{array}{l}135 \\
(174 \%)\end{array}$ & 6.7 & + & negative & negative \\
\hline
\end{tabular}

1 Surface area

${ }^{2}$ Inulin clearance

3 Clearance of para-aminohippurate

4 Renal tubular transport maximum for paraaminohippurate
${ }^{5}$ Bladder neck contracture

${ }^{6}$ White blood cells per high power field.

7 Uretero-pelvic

${ }^{8}$ Figures in parentheses indicate percent of normal function 
Alterations in renal cortical blood flow in infants and children with urinary tract infections 337

\begin{tabular}{|c|c|c|c|c|c|c|c|}
\hline \multicolumn{3}{|l|}{ of study } & \multicolumn{2}{|c|}{$\begin{array}{l}\text { Antimicro- } \\
\text { bial therapy }\end{array}$} & \multirow{2}{*}{ 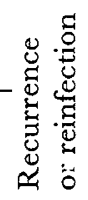 } & \multirow{2}{*}{ 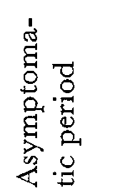 } & \multirow[b]{2}{*}{ Comments } \\
\hline $\begin{array}{l}\text { Urine } \\
\text { culture }\end{array}$ & $\begin{array}{l}\text { Urologic } \\
\text { findings }\end{array}$ & $\begin{array}{l}\text { Duration } \\
\text { fromonset }\end{array}$ & On & Off & & & \\
\hline 2000 col. $* / \mathrm{m}$ & $\begin{array}{l}\mathrm{BNC}^{5}, \mathrm{rt} \text {. ureteral } \\
\text { reflux }\end{array}$ & $\begin{array}{l}4 \\
\text { months }\end{array}$ & $\begin{array}{l}4 \\
\text { months }\end{array}$ & 0 & & none & \\
\hline $\begin{array}{l}100,000 \\
\text { col./ml } \\
\text { enterococci }\end{array}$ & $\begin{array}{l}\text { BNG, rt. ureteral } \\
\text { reflux, mild } \\
\text { rt. hydronephrosis }\end{array}$ & $\begin{array}{l}13 \\
\text { months }\end{array}$ & 8 & 1 & & months & \\
\hline $\begin{array}{l}18,000 \\
\text { col. } / \mathrm{ml} \\
\text { E. coli }\end{array}$ & $\begin{array}{l}\text { meatal stenosis } \mathrm{BNC} \text {, } \\
\text { lt. U-P }{ }^{7} \text { holdup mild } \\
\text { lt. hydronephrosis, } \\
\text { lt. ureteral reflux }\end{array}$ & $\begin{array}{l}5 \\
\text { months }\end{array}$ & $\begin{array}{l}5 \\
\text { months }\end{array}$ & 0 & & $\begin{array}{l}5 \\
\text { months }\end{array}$ & $\begin{array}{l}\text { ureteral dilatation and } \\
\text { circumcision at } 6 \text { months } \\
\text { of age }\end{array}$ \\
\hline negative & $\begin{array}{l}\text { mild BNG, mild } \\
\text { lt. hydronephrosis }\end{array}$ & $\begin{array}{l}25 \\
\text { months }\end{array}$ & month & 19 & & $\begin{array}{l}18 \\
\text { months }\end{array}$ & \\
\hline negative & $\begin{array}{l}\text { mild BNG, mild } \\
\text { lt. hydronephrosis }\end{array}$ & $\begin{array}{l}38 \\
\text { months }\end{array}$ & 0 & 13 & & 13 & \\
\hline $\begin{array}{l}100,000 \\
\text { col./ml } \\
\text { E. coli }\end{array}$ & $\begin{array}{l}\text { rt. hydronephrosis } \\
\text { rt. hydroureter }\end{array}$ & $\begin{array}{l}4 \\
\text { months }\end{array}$ & $\begin{array}{l}4 \\
\text { months }\end{array}$ & 0 & & none & $\begin{array}{l}\text { suprapubic cystotomy at } \\
2 \text { months of age. At } 4 \\
\text { months of age resection of } \\
\text { posterior urethral valves } \\
\text { and } Y-V \text { plasty performed }\end{array}$ \\
\hline negative & rt. ureteral reflux & $\begin{array}{l}6 \\
\text { months }\end{array}$ & $\begin{array}{l}6 \\
\text { months }\end{array}$ & 0 & & $\begin{array}{l}2 \\
\text { months }\end{array}$ & $\begin{array}{l}\text { at } 4 \text { months of age } \\
\text { urethral dilatation and } \\
\text { circumcision performed }\end{array}$ \\
\hline $\begin{array}{l}100,000 \\
\text { col. } / \mathrm{ml} \\
\text { aerobacter, } \\
\text { enterococci } \\
\text { E. coli }\end{array}$ & $\begin{array}{l}\text { BNG, gaping ureters. } \\
\text { No reflux }\end{array}$ & $\begin{array}{l}6 \\
\text { months }\end{array}$ & $\begin{array}{l}4 \\
\text { months }\end{array}$ & $\begin{array}{l}2 \\
\text { months }\end{array}$ & 1 & $\begin{array}{l}6 \\
\text { months }\end{array}$ & $\begin{array}{l}8 \text { months urethral } \\
\text { dilatation performed }\end{array}$ \\
\hline negative & rt. ureteral reflux & $\begin{array}{l}13 \\
\text { months }\end{array}$ & months & months & 0 & months & \\
\hline negative & $\begin{array}{l}\text { mild BNG; retention } \\
\text { of contrast media in } \\
\text { collecting system for } \\
2 \text { hours }\end{array}$ & $\begin{array}{l}22 \\
\text { months }\end{array}$ & $\begin{array}{l}6 \\
\text { months }\end{array}$ & $\begin{array}{l}16 \\
\text { months }\end{array}$ & 2 & none & $\begin{array}{l}\text { urethral dilatation at } \\
2 \text { years }\end{array}$ \\
\hline negative & negative & $\begin{array}{l}27 \\
\text { months }\end{array}$ & $\begin{array}{l}5 \\
\text { months }\end{array}$ & & 0 & months & \\
\hline
\end{tabular}

* Colonies 


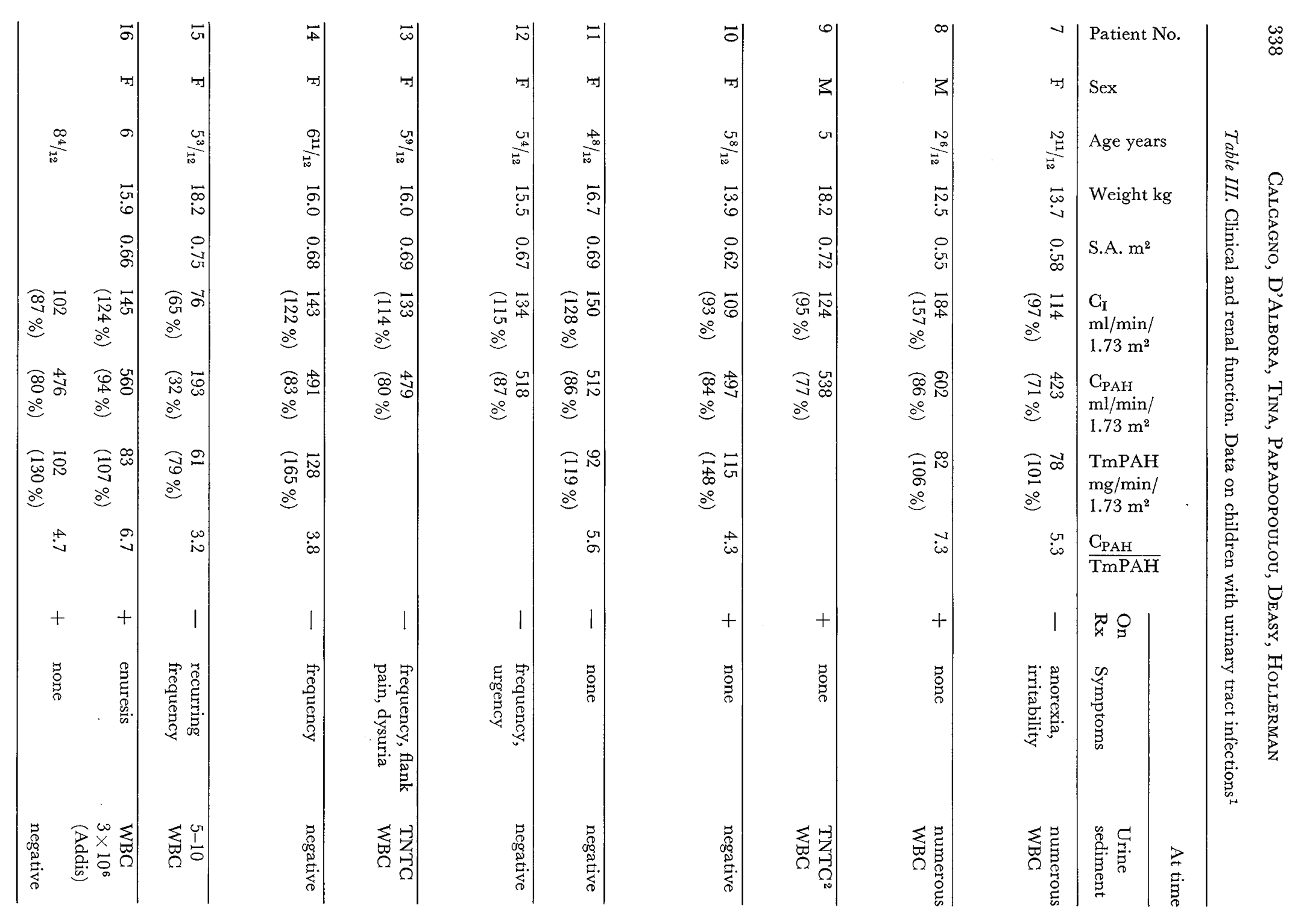


Alterations in renal cortical blood flow in infants and children with urinary tract infections 339

\begin{tabular}{|c|c|c|c|c|c|c|c|}
\hline \multicolumn{3}{|l|}{ of study } & \multicolumn{2}{|c|}{$\begin{array}{l}\text { Antimicro- } \\
\text { bial therapy }\end{array}$} & \multirow{2}{*}{ 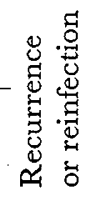 } & \multirow{2}{*}{ 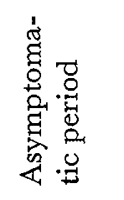 } & \multirow[b]{2}{*}{ Comments } \\
\hline $\begin{array}{l}\text { Urine } \\
\text { culture }\end{array}$ & $\begin{array}{l}\text { Urologic } \\
\text { findings }\end{array}$ & $\begin{array}{l}\text { Duration } \\
\text { fromonset }\end{array}$ & On & Off & & & \\
\hline $\begin{array}{l}100,000 \\
\text { col./ml } \\
E . \text { coli and } \\
\text { proteus } \\
\text { vulgarus }\end{array}$ & $\begin{array}{l}\text { meatal stenosis, } \\
\text { bladder trabeculations }\end{array}$ & 3 weeks & 0 & 0 & 0 & 0 & $\begin{array}{l}\text { first attack requiring } \\
\text { medical care }\end{array}$ \\
\hline negative & $\begin{array}{l}\text { rt. hydronephrosis } \\
\text { rt. hydroureter } \\
\text { rt. ureterocele } \\
\text { bilateral reflux } \\
\text { posterior urethral valves }\end{array}$ & $\begin{array}{l}6 \\
\text { months }\end{array}$ & $\begin{array}{l}6 \\
\text { months }\end{array}$ & 0 & 0 & $\begin{array}{l}5 \\
\text { months }\end{array}$ & $\begin{array}{l}\text { removal of posterior } \\
\text { urethral valves and rt. } \\
\text { ureteral reimplantation } \\
\text { following clearance } \\
\text { studies }\end{array}$ \\
\hline $\begin{array}{l}100,000 \\
\text { col./ml } \\
E . \text { coli } \\
\text { pseudomonos }\end{array}$ & 'cord bladder' & $\begin{array}{l}5 \\
\text { months }\end{array}$ & $\begin{array}{l}3 \\
\text { months }\end{array}$ & $\begin{array}{l}2 \\
\text { months }\end{array}$ & 0 & 0 & $\begin{array}{l}\text { traumatic injury and } \\
\text { neurogenic bladder }\end{array}$ \\
\hline $\begin{array}{l}100,000 \\
\text { col. } / \mathrm{ml} \\
\text { E. coli }\end{array}$ & BNG, meatal stenosis & $\begin{array}{l}9 \\
\text { months }\end{array}$ & $\begin{array}{l}9 \\
\text { months }\end{array}$ & 0 & 2 & 0 & $\begin{array}{l}\text { Nephrotic syndrome } \\
\text { confirmed by renal } \\
\text { biopsy; no pyelonephritis } \\
\text { on biopsy. Urethral } \\
\text { dilatation and meatotomy } \\
\text { after clearance test }\end{array}$ \\
\hline negative & $\mathrm{BNC}$ & $\begin{array}{l}17 \\
\text { months }\end{array}$ & $\begin{array}{l}9 \\
\text { months }\end{array}$ & $\begin{array}{l}8 \\
\text { months }\end{array}$ & 2 & none & $\begin{array}{l}\text { Therapy: urethral dilata- } \\
\text { tion and long-term } \\
\text { antimicrobial therapy }\end{array}$ \\
\hline negative & $\begin{array}{l}\text { double collecting } \\
\text { system (left) }\end{array}$ & $\begin{array}{l}10 \\
\text { months }\end{array}$ & $\begin{array}{l}3 \\
\text { months }\end{array}$ & $\begin{array}{l}7 \\
\text { months }\end{array}$ & 1 & none & $\begin{array}{l}\text { short-term antimicrobial } \\
\text { thera py }(\mathrm{S}) \text {. Renal biopsy } \\
\text { at time of clearance. } \\
\text { Failed to reveal evidence } \\
\text { of infection }\end{array}$ \\
\hline $\begin{array}{l}100,000 \\
\text { col./ml } \\
\text { coliform }\end{array}$ & $\mathrm{BNC}$ & $\begin{array}{l}24 \\
\text { months }\end{array}$ & 0 & $\begin{array}{l}12 \\
\text { months }\end{array}$ & 2 & $\begin{array}{l}12 \\
\text { months }\end{array}$ & $\begin{array}{l}\text { previous short-term anti- } \\
\text { microbial therapy }(\mathrm{S}) \text { for } 2 \\
\text { culturally proven previous } \\
\text { urinary tract infections }\end{array}$ \\
\hline $\begin{array}{l}48,000 \\
\text { col. } / \mathrm{ml} \\
E . \text { coli }\end{array}$ & BNG & $\begin{array}{l}12 \\
\text { months }\end{array}$ & $\begin{array}{l}4 \\
\text { months }\end{array}$ & $\begin{array}{l}8 \\
\text { months }\end{array}$ & 1 & none & $\begin{array}{l}\text { urethral dilatation and } \\
\text { meatotomy done at age } \\
6^{3} / 12 \text { years. Renal biopsy } \\
\text { at time of clearance failed } \\
\text { to reveal infection of kidney }\end{array}$ \\
\hline $\begin{array}{l}\text { aerobacter } \\
13,000 \\
\text { col. } / \mathrm{ml}\end{array}$ & $\begin{array}{l}\text { BNG, meatal stenosis } \\
\text { rt. upper tract } \\
\text { dilated }\end{array}$ & $\begin{array}{l}3 \\
\text { months }\end{array}$ & $\begin{array}{l}2 \\
\text { months }\end{array}$ & $\begin{array}{l}1 \\
\text { month }\end{array}$ & 1 & none & $\begin{array}{l}\text { urethral dilatation and } \\
\text { meatotomy done at time } \\
\text { of clearance }\end{array}$ \\
\hline $\begin{array}{l}22,000 \\
\text { col. } / \mathrm{ml} \\
\text { E. coli }\end{array}$ & meatal stenosis & $\begin{array}{l}16 \\
\text { months }\end{array}$ & $\begin{array}{l}9 \\
\text { months }\end{array}$ & $\begin{array}{l}7 \\
\text { months }\end{array}$ & 2 & $\begin{array}{l}4 \\
\text { months }\end{array}$ & $\begin{array}{l}\text { urethral dilatation and } \\
\text { long-term antimicrobial } \\
\text { therapy }\end{array}$ \\
\hline negative & meatal stenosis & $\begin{array}{l}44 \\
\text { months }\end{array}$ & $\begin{array}{l}10 \\
\text { months }\end{array}$ & $\begin{array}{l}18 \\
\text { months }\end{array}$ & 1 & $\begin{array}{l}12 \\
\text { months }\end{array}$ & \\
\hline
\end{tabular}


Table III. (Continued)

\begin{tabular}{|c|c|c|c|c|c|c|c|c|c|c|c|}
\hline \multirow{2}{*}{ 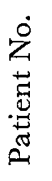 } & \multirow[b]{2}{*}{ 莌 } & \multirow{2}{*}{ 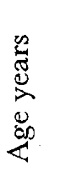 } & \multirow{2}{*}{ 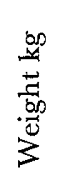 } & \multirow{2}{*}{$\begin{array}{l}\stackrel{N}{\Xi} \\
\dot{\bigsqcup} \\
\dot{\Omega}\end{array}$} & \multirow{2}{*}{ 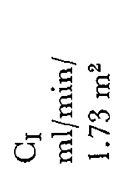 } & \multirow{2}{*}{ 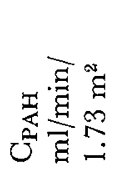 } & \multirow{2}{*}{ 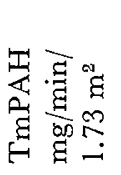 } & \multirow{2}{*}{ 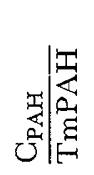 } & \multicolumn{3}{|r|}{ At time } \\
\hline & & & & & & & & & $\begin{array}{l}\text { On } \\
\mathrm{Rx}\end{array}$ & Symptoms & $\begin{array}{l}\text { Urine } \\
\text { sediment }\end{array}$ \\
\hline \multirow[t]{2}{*}{17} & $\mathrm{~F}$ & $74 / 12$ & 35.0 & 1.08 & $\begin{array}{l}106 \\
(91 \%)\end{array}$ & $\begin{array}{l}479 \\
(80 \%)\end{array}$ & $\begin{array}{l}104 \\
(134 \%)\end{array}$ & 4.6 & - & frequency & negative \\
\hline & & $96 / 12$ & 44.5 & 1.31 & $\begin{array}{l}157 \\
(134 \%)\end{array}$ & $\begin{array}{l}680 \\
(114 \%)\end{array}$ & & & - & none & negative \\
\hline \multirow[t]{2}{*}{18} & $\mathrm{~F}$ & $69 / 12$ & 33.2 & 1.05 & $\begin{array}{l}129 \\
(110 \%)\end{array}$ & $\begin{array}{l}489 \\
(82 \%)\end{array}$ & $\begin{array}{l}72 \\
(93 \%)\end{array}$ & 6.8 & - & none & negative \\
\hline & & $8^{2} / 12$ & 40.0 & 1.20 & $\begin{array}{l}125 \\
(107 \%)\end{array}$ & $\begin{array}{l}457 \\
(77 \%)\end{array}$ & & & - & none & negative \\
\hline 19 & $\mathrm{~F}$ & $6 \% / 12$ & 20.7 & 0.85 & $\begin{array}{l}148 \\
(126 \%)\end{array}$ & $\begin{array}{l}623 \\
(104 \%)\end{array}$ & $\begin{array}{l}100 \\
(129 \%)\end{array}$ & 6.2 & - & none & negative \\
\hline 20 & $\mathrm{~F}$ & $78 / 12$ & 25.9 & 0.98 & $\begin{array}{l}140 \\
(120 \%)\end{array}$ & $\begin{array}{l}574 \\
(97 \%)\end{array}$ & $\begin{array}{l}122 \\
(157 \%)\end{array}$ & 4.7 & - & frequency & negative \\
\hline$\overline{21}$ & $F$ & $13^{4} / 12$ & 30.0 & 1.05 & $\begin{array}{l}56 \\
(48 \%)\end{array}$ & $\begin{array}{l}485 \\
(82 \%)\end{array}$ & $\begin{array}{l}100 \\
(129 \%)\end{array}$ & 4.9 & - & frequency & negative \\
\hline \multirow[t]{2}{*}{22} & $\mathrm{~F}$ & $13^{6} / 12$ & 36.8 & 1.22 & $\begin{array}{l}13 \mathrm{I} \\
(119 \%)\end{array}$ & $\begin{array}{l}744 \\
(125 \%)\end{array}$ & & & + & fatigue & $\begin{array}{l}15-20 \\
\text { WBG/ } \\
\text { HPF }\end{array}$ \\
\hline & & $15^{11} / 12$ & 42.0 & 1.50 & $\begin{array}{l}173 \\
(148 \%)\end{array}$ & $\begin{array}{l}394 \\
(66 \%)\end{array}$ & $\begin{array}{l}68 \\
(88 \%)\end{array}$ & 5.8 & - & fatigue & negative \\
\hline 23 & $\mathrm{~F}$ & $12^{4} / 12$ & 45.4 & 1.62 & $\begin{array}{l}165 \\
(141 \%)\end{array}$ & $\begin{array}{l}426 \\
(72 \%)\end{array}$ & & & - & fatigue & $\begin{array}{l}5-10 \\
\text { WBC }\end{array}$ \\
\hline
\end{tabular}

${ }^{1}$ See table II for abbreviations ${ }^{2}$ Too numerous to count

standard deviation below or at the borderline for the adult mean value for $\mathrm{C}_{\mathrm{PAH}}$. The average value of these experimental clearances is $82 \%$, excluding patients without documented urinary tract infections, and $86 \%$ when these patients are included; this is in contrast to the 'normal' of $100 \%$. Of the 27 experimental points (fig. 1), 21 are below the line representing the average $\mathrm{C}_{\mathrm{PAH}}$ for children. The difference between $100 \%$ and $86 \%$ is highly significant, with $p<0.001$. The lower $\mathrm{C}_{\mathrm{PAH}}$ value could not be related to the frequency of recurrence nor to the duration of the urinary tract infection. In addition, several patients with reduced $\mathrm{C}_{\mathrm{PAH}}$ measurements failed to demonstrate morbid symptoms, abnormal urinary sediment, or bacteriuria.

The restudy of four infants revealed a return to normal values in two in whom values had previously been low, a continued low value in one, and a persistent normal value in the other. In this small series, therefore, only one of three infants failed to recover this function at the time of retesting. In contrast, recovery was less impressive in the children studied. Six of 17 children were observed to have decreased initial $\mathrm{C}_{\mathrm{PAH}}$ values. If borderline values for $\mathrm{C}_{\mathrm{PAH}}$ are also included, then initial testing revaled 9 of 17 or $52 \%$ had decreased renal blood flow. In four children, clearances were 
Alterations in renal cortical blood flow in infants and children with urinary tract infections 341

\begin{tabular}{|c|c|c|c|c|c|c|c|}
\hline \multicolumn{3}{|l|}{ of study } & \multicolumn{2}{|c|}{$\begin{array}{l}\text { Antimicro- } \\
\text { bial therapy }\end{array}$} & \multirow{2}{*}{ 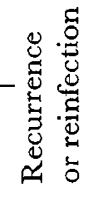 } & \multirow{2}{*}{ 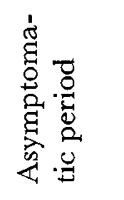 } & \multirow[b]{2}{*}{ Comments } \\
\hline $\begin{array}{l}\text { Urine } \\
\text { culture }\end{array}$ & $\begin{array}{l}\text { Urologic } \\
\text { findings }\end{array}$ & $\begin{array}{l}\text { Duration } \\
\text { from onset }\end{array}$ & On & Off & & & \\
\hline negative & BNC, meatal stenosis & $\begin{array}{l}22 \\
\text { months }\end{array}$ & $\begin{array}{l}10 \\
\text { months }\end{array}$ & $\begin{array}{l}12 \\
\text { months }\end{array}$ & 0 & 0 & $\begin{array}{l}\text { repeat urethral dilatations } \\
\text { and long-term anti- } \\
\text { microbial therapy }\end{array}$ \\
\hline negative & none & $\begin{array}{l}48 \\
\text { months }\end{array}$ & $\begin{array}{l}18 \\
\text { months }\end{array}$ & $\begin{array}{l}8 \\
\text { months }\end{array}$ & 0 & $\begin{array}{l}14 \\
\text { months }\end{array}$ & \\
\hline negative & $\mathrm{BNC}$ & $\begin{array}{l}9 \\
\text { months }\end{array}$ & $\begin{array}{l}1 \\
\text { month }\end{array}$ & $\begin{array}{l}8 \\
\text { months }\end{array}$ & 1 & $\begin{array}{l}8 \\
\text { months }\end{array}$ & $\begin{array}{l}\text { dilatation and long-term } \\
\text { antimicrobial therapy }\end{array}$ \\
\hline negative & none & $\begin{array}{l}26 \\
\text { months }\end{array}$ & $\begin{array}{l}12 \\
\text { months }\end{array}$ & $\begin{array}{l}5 \\
\text { months }\end{array}$ & 0 & $\begin{array}{l}17 \\
\text { months }\end{array}$ & \\
\hline negative & negative & $\begin{array}{l}11 \\
\text { months }\end{array}$ & $\begin{array}{l}5 \\
\text { months }\end{array}$ & $\begin{array}{l}6 \\
\text { months }\end{array}$ & 1 & $\begin{array}{l}5 \\
\text { months }\end{array}$ & $\begin{array}{l}\text { single attack, renal clear- } \\
\text { ances after one year } \\
\text { therapy }\end{array}$ \\
\hline $\begin{array}{l}100,000 \\
\text { col. } / \mathrm{ml} \\
\text { E. coli }\end{array}$ & $\begin{array}{l}\text { BNC, meatal stenosis. } \\
\text { Rt. kidney enlarged } \\
\text { with blunting of } \\
\text { superior calcyx }\end{array}$ & months & $\begin{array}{l}\text { question- } \\
\text { able }\end{array}$ & & 1 & 0 & \\
\hline negative & $\begin{array}{l}\text { mild BNC, dilatation } \\
\text { and blunting of } \\
\text { rt. upper calxcy }\end{array}$ & $\begin{array}{l}40 \\
\text { months }\end{array}$ & $\begin{array}{l}3 \\
\text { months }\end{array}$ & 0 & 4 & 0 & $\begin{array}{l}\text { repeat urethral dilatation } \\
\text { and sporadic antimicrobial } \\
\text { therapy }\end{array}$ \\
\hline $\begin{array}{l}30,000 \\
\text { col. } / \mathrm{ml} \\
\text { E. coli }\end{array}$ & mild BNC & $\begin{array}{l}35 \\
\text { months }\end{array}$ & $\begin{array}{l}24 \\
\text { months }\end{array}$ & 0 & 0 & 0 & \\
\hline negative & negative & $\begin{array}{l}64 \\
\text { months }\end{array}$ & 0 & $\begin{array}{l}30 \\
\text { months }\end{array}$ & 0 & 0 & $\begin{array}{l}\text { renal biopsy: minimal } \\
\text { changes consistent with } \\
\text { acute pyelonephritis }\end{array}$ \\
\hline $\begin{array}{l}40,000 \\
\text { col. } / \mathrm{ml} \\
\text { E. coli }\end{array}$ & $\begin{array}{l}\text { rt. ureteral reflux. } \\
\text { Mild BNC }\end{array}$ & $\begin{array}{l}26 \\
\text { months }\end{array}$ & $\begin{array}{l}24 \\
\text { months }\end{array}$ & $\begin{array}{l}2 \\
\text { months }\end{array}$ & 4 & 0 & $\begin{array}{l}\text { renal biopsy: minimal } \\
\text { changes consistent with } \\
\text { acute pyelonephritis }\end{array}$ \\
\hline
\end{tabular}

remeasured, and three demonstrated decreased or low values in comparison with values which had been normal or borderline; function in one patient returned to normal. These data suggest that infants, in comparison with children, may have a greater potential for reversing abnormal $\mathrm{C}_{\mathrm{PAH}}$ values. Further experiments in both infants and children will be needed to verify and determine the significance of this preliminary observation.

PAH clearances were found to be reduced by $22 \%$ in infected rats inoculated repetitively with enterococci every three weeks for 21 weeks, even though the creatinine clearance was unchanged throughout the course of infection [13]. On the basis of their experimental results, these investigators related the functional alterations to a progression of ischemic reaction in the cortex and the medulla. This reaction ultimately became a pathologic process resembling that found in advanced chronic pyelonephritis in man.

An experimental model utilizing microangiographic and histologic techniques to study experimental pyelonephritis in rabbits and rats revealed that the primary injury occurred at the post-glomerular level [14]. The acute inflammatory phase of the infection was associated with irregular constriction of intertubular capillaries and destruction of cortical tubules. The presence 
Table IV. Clinical and renal functional data on children without documented urinary tract infection but associated with possible urinary tract obstruction ${ }^{\text {I }}$

\begin{tabular}{|c|c|c|c|c|c|c|c|c|c|c|c|}
\hline \multirow{2}{*}{ 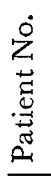 } & \multirow[b]{2}{*}{$\underset{\mathscr{n}}{\not{n}}$} & \multirow{2}{*}{ 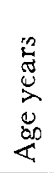 } & \multirow{2}{*}{ 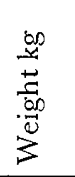 } & \multirow[b]{2}{*}{$\begin{array}{l}\stackrel{2}{\Xi} \\
\dot{\zeta} \\
\dot{\Omega}\end{array}$} & \multirow[b]{2}{*}{ せ } & \multirow[b]{2}{*}{ 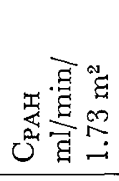 } & \multirow{2}{*}{ 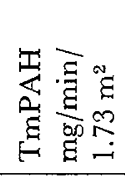 } & \multirow{2}{*}{ 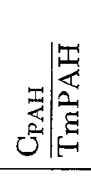 } & \multicolumn{3}{|r|}{ At time } \\
\hline & & & & & & & & & $\begin{array}{l}\text { On } \\
\mathrm{Rx}\end{array}$ & Symptoms & $\begin{array}{l}\text { Urine } \\
\text { sediment }\end{array}$ \\
\hline 24 & $\mathrm{~F}$ & 2 & 11.0 & 0.46 & $\begin{array}{l}111 \\
(95 \%)\end{array}$ & $\begin{array}{l}536 \\
(90 \%)\end{array}$ & $\begin{array}{l}88 \\
(135 \%)\end{array}$ & 6.1 & - & none & negative \\
\hline
\end{tabular}

\begin{tabular}{|c|c|c|c|c|c|c|c|c|c|c|c|}
\hline 25 & $\mathrm{~F}$ & $3^{6} / 12$ & 16.0 & 0.66 & $\begin{array}{l}158 \\
(135 \%)\end{array}$ & $\begin{array}{l}557 \\
(94 \%)\end{array}$ & $\begin{array}{l}137 \\
(177 \%)\end{array}$ & 4.1 & + & urinary frequency & negative \\
\hline 26 & $\mathrm{~F}$ & $37 / 12$ & 16.3 & 0.64 & $\begin{array}{l}222 \\
(190 \%)\end{array}$ & $\begin{array}{l}750 \\
(126 \%)\end{array}$ & $\begin{array}{l}132 \\
(170 \%)\end{array}$ & 5.7 & + & none & negative \\
\hline 27 & $\mathrm{~F}$ & $6^{10} / 12$ & 24.5 & 0.95 & $\begin{array}{l}185 \\
(158 \%)\end{array}$ & $\begin{array}{l}747 \\
(126 \%)\end{array}$ & $\begin{array}{l}122 \\
(157 \%)\end{array}$ & 6.1 & - & megacystis revealed & during \\
\hline
\end{tabular}

${ }^{i}$ See table II for abbreviations.

of diminished renal plasma flow in the infants and children observed in the present study appears comparable to the experimental findings noted in the rabbits and rats.

Three subjects in this study demonstrated a reduction in both glomerular filtration rate and renal plasma flow. Impaired renal function due to bacterial endotox-

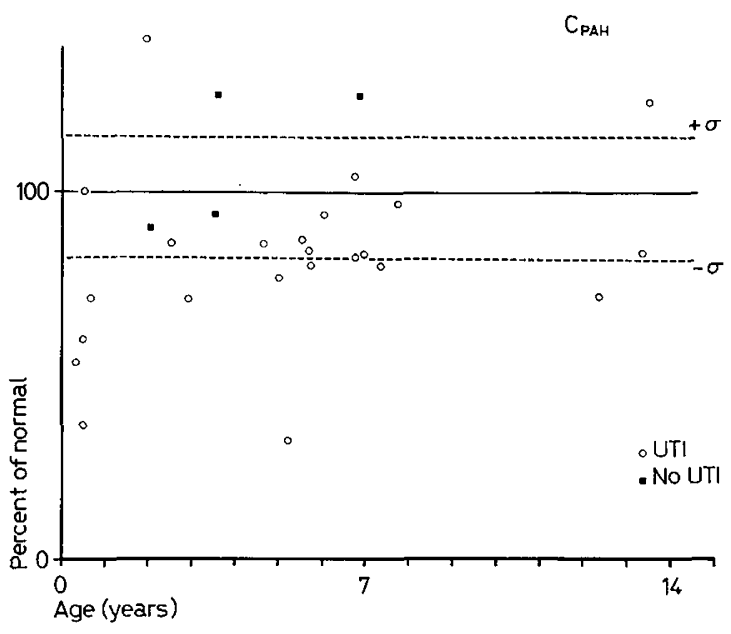

Fig. 1. CPAH obtained in infants and children with documented urinary tract infections (UTI) and children without proven infection. The solid line presents the 100-percent value for normal children. The dotted lines are \pm one standard deviation of the average value for normal children. Twenty-one of twenty-seven points are below the solid line. By the binomial test, the difference between $100 \%$ and $86 \%$ is highly significant with $\mathrm{p}<0.001$. in has been shown to reduce renal plasma flow, glomerular filtration rate, $\mathrm{E}_{\mathrm{PAH}}$, and urinary output. All these changes appeared secondary to renal vasoconstriction [12]. In the one infant with a possible diminished glomerular filtration rate, $E$. coli were present at the time of testing, and in one of two children, enterococci were isolated from the urine at the time of study. The cause of reduced renal function in these two subjects with bacteriuria is moot.

Data on tubular excretory capacity for para-aminohippurate in children with urinary tract infections are not available. In normal growing infants, adult values were obtained by 18 months of age [24]. The finding of values greater than one standard deviation above the mean in 3 of the 4 children without documented urinary tract infections and in 8 of the 14 subjects tested raises several questions concerning the specificity of PAH as a measure of tubular mass in these patients. In the group with urinary tract infections, the following possibilities exist:

(1) Acetate and lactate are substances known to increase PAH transport in vitro and in vivo [26]; however, no information is available on the urinary excretion rates or renal vein concentration of these metabolites in pyelonephritis.

(2) The early pathologic findings in experimental pyelonephritis in animals include marked hypertrophy and hyperplasia of the collecting duct epithelium. After repetitive infections, cellular hypertrophy is less marked, but an increase in stromal tissue is apparent; this is associated with dilatation of the lumina. Hyperplasia has been demonstrated in response to active loss of tissue or to increased nutrition of the organs through hypervascularity [11]. The TmPAH data in the pres- 
Alterations in renal cortical blood flow in infants and children with urinary tract infections 343

\begin{tabular}{|c|c|c|c|c|c|c|c|}
\hline \multicolumn{3}{|l|}{ of study } & \multicolumn{2}{|c|}{$\begin{array}{l}\text { Antimicro- } \\
\text { bial therapy }\end{array}$} & \multirow{2}{*}{ 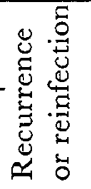 } & \multirow{2}{*}{ 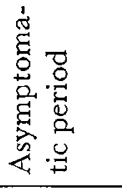 } & \multirow[b]{2}{*}{ Comments } \\
\hline $\begin{array}{l}\text { Urine } \\
\text { culture }\end{array}$ & $\begin{array}{l}\text { Urologic } \\
\text { findings }\end{array}$ & $\begin{array}{l}\text { Duration } \\
\text { from onset }\end{array}$ & On & Off & & & \\
\hline negative & $\mathrm{BNC}$ & $\begin{array}{l}6 \\
\text { months }\end{array}$ & 0 & $\begin{array}{l}5 \\
\text { months }\end{array}$ & 2 & $\begin{array}{l}5 \\
\text { months }\end{array}$ & $\begin{array}{l}\text { two previous undocument- } \\
\text { ed urinary tract infections } \\
\text { treated with urethral } \\
\text { dilatations and short-term } \\
\text { chemotherapy }\end{array}$ \\
\hline negative & $\begin{array}{l}\text { urethritis, meatal } \\
\text { stenosis }\end{array}$ & $\begin{array}{l}9 \\
\text { months }\end{array}$ & $\begin{array}{l}9 \\
\text { months }\end{array}$ & 0 & 0 & 0 & \\
\hline negative & negative & $\begin{array}{l}30 \\
\text { months }\end{array}$ & $\begin{array}{l}6 \\
\text { months }\end{array}$ & $\begin{array}{l}24 \\
\text { months }\end{array}$ & 0 & $\begin{array}{l}24 \\
\text { months }\end{array}$ & $\begin{array}{l}\text { urethral dilatation at } \\
37 \text { months of age }\end{array}$ \\
\hline
\end{tabular}

study of genitourinary tract following acute glomerulonephritis 2 years previously

ent study are in agreement with the pathologic data obtained in rats subjected to experimental pyelonephritis. In these animals, hyperplasia was observed during the first week of the disease [13].

An examination of renal plasma flow per unit of tubular mass may help in some instances to define the nature of the renal disorder. Twenty-two subjects in this study were tested for both $\mathrm{C}_{\mathrm{PAH}}$ and $\mathrm{TmPAH}$. The mean ratios of $\mathrm{C}_{\mathrm{PAH}} / \mathrm{TmPAH}$ were: infants, 6.4 ; children, 5.3 ; and children without documented urinary tract infection, 5.1 . The ratio $\left(\mathrm{C}_{\mathrm{PAH}} / \mathrm{TmPAH}\right)$ is lower in all three groups than the reported normal value of 7.7. The most plausible explanation for the decreased ratios is the high values of TmPAH which averaged 87,95 , and $120 \mathrm{mg} / \mathrm{min} / 1.73 \mathrm{~m}^{2}$ in the three groups respectively. In initial renal functional studies in those patients demonstrating a reduced ratio, 13 of 16 showed normal values of $\mathrm{C}_{\mathrm{PAH}}$. These findings may reflect renal ischemia in individual units of proximal tubular tissue. The renal clearance of PAH is believed to measure cortical blood flow, which in turn accounts for $90 \%$ of the total kidney blood flow. Animal studies have shown that the medulla, papilla, capsule, and perirenal fat account for the remaining $10 \%$ [3]. Assuming that $\mathrm{PAH}$ measures renal plasma flow and tubular excretory capacity, the data in the current study of pyelonephritis support the view that the post-glomerular capillaries and tubular structure within the cortex are involved early in urinary tract infections.

It is possible that some infants are born with a defect in cortical blood supply rendering them susceptible to urinary tract infections. Alternatively, cortical ischemia could be secondary to either obstruction or infection. In the patients studied, none had an obstructive lesion of such a nature as to make this a likely possibility Rather, the renal ischemia would appear to be a consequence of the acute reversible inflammatory process. Infants, in comparison with children, may have a greater tendency to or capacity for reversal of diminished renal plasma flow, although this speculation requires further observation and documentation.

The localization of chronic pyelonephritis in the medullary portion of the kidney, with a concomitant reduction in the urinary concentrating capacity, has received careful documentation $[5,6]$. All of our patients showed a urinary specific gravity of greater than 1.020 in randomly collected urine specimens; in 22 patients, the values were greater than 1.025. Published data [28] on 22 children with acute pyelonephritis in whom a urinary concentrating defect persisted for four to six weeks after subsidence of fever are not comparable to those of the present study since, with one exception, the present subjects were tested after subsidence of their symptoms. At that time, no decrease in urinary concentrating capacity was found in any.

The renal vascular changes demonstrated in this study to persist in the absence of clinical and/or laboratory evidence of urinary tract infections emphasize the need for caution in identifying the prognosis of children with pyelonephritis and the need for careful long-term evaluation.

\section{Summary}

(1) Thirteen of 23 infants and children with urinary tract infections were found to have a significant reduction in renal plasma flow as measured by para-aminohippurate clearance $(p<0.001)$. The variations ob- 
tained were more than one standard deviation below the normal values for their appropriate ages.

(2) In longitudinal studies obtained 5 to 29 months after initial determinations, 1 of 4 infants and 3 of 4 children continued to show a reduction in $\mathrm{C}_{\mathrm{PAH}}$.

(3) Inulin clearance was normal in all patients except those in whom a reduction in both PAH and inulin clearances was demonstrated.

(4) TmPAH was reduced in only 2 of the 18 subjects with urinary tract infections. Approximately $50 \%$ of the 18 subjects had TmPAH values greater than one standard deviation above the normal.

(5) The mean ratio of $\mathrm{CPAH}_{\mathrm{PA}} \mathrm{TmPAH}$ in these subjects was reduced, in comparison with the normal value for children.

(6) These observations suggest the presence of renal ischemia in individual units of proximal tubular tissue during the course of urinary tract infection.

\section{References and Notes}

1. BALINT, P.: The reliability of PAH clearance as a measure of renal plasma flow. Proc. 2nd international Congress of Nephrology, Prague, Czechoslovakia, 1964, p. 84 (Excerpta Medica Foundation under the Berne Convention).

2. Balint, P. and Forgacs, I.: On the storage of inulin and PAH in renal tissue. Acta physiol.hung. 15: 15 (1959).

3. BARger, A. C. : Cortical and medullary blood flow in the kidney; in: Progress in pyelonephritis (ed. KAss, E.H.), p.398 (Davis, Philadelphia, Pa. 1965).

4. Bradley, S.E.; Bradley, G.P.; Tyson, G.I.; Gurry, J.J. and Blake, W.D.: Renal function in renal diseases. Amer.J. Med. 9: 766 (1950).

5. BRoD, J.: Chronic pyelonephritis. Lancet $i: 973$ (1956).

6. Brod, J.; Prat, V. and DeJdAR, R.: Early functional diagnosis of chronic pyelonephritis with some remarks on the pathogenesis of the pyelonephritis contracted kidney; in: Biology of pyelonephritis, p.311 (Little, Brown, Boston, Mass. 1960).

7. Bull, G.M. and Metaxas, P.: The theory and application of clearance methods for determining renal blood and lymph flow. Clin. Sci. 23: 515 (1962).

8. Burke, E. C.: Commentary on urinary tract infections in children. Mayo Clin. Proc. 40: 113 (1965).

9. Calcagno, P.L. and Lowe, C.U.: Substrate induced renal tubular maturation. J. Pediat. 63: 851 (1963).
10. Calcagno, P.L. and Rubin, M. I.: Renal extraction of para-aminohippurate in infants and children. J. clin. Invest. 42: 1632 (1963).

11. Geschickter, C.F.: The causes of tissue overgrowth: human cancerogenesis. Georgetown med. Bull. 15: 142 (1961).

12. Gillenwater, J.Y.; Dooley, E. S. and Frohlich, E. D.: Effects of endotoxin on renal function and hemodynamics. Amer.J. Physiol. 205: 293 (1963).

13. Gonick, H. G.; GoldberG, G.; Rubini, M.E. and Guze, L.B.: Functional abnormalities in experimental pyelonephritis. I. Studies of concentrating ability. Nephron 2: 193 (1965).

14. HrLl, G. S. : Experimental pyelonephritis : A microangiographic and histologic study of cortical vascular changes. Bull.Johns Hopk. Hosp. 119: 79 (1966).

15. Hubbard, R.S. and Loomis, T.A.: The determination of inulin. J. biol. Chem. 145: 641 (1942).

16. Jones, S.G.; Lruien, O.M. and Rogers, L.S.: Renal pelvic pressure and its relation to renal hemodynamics. J. Urol. 90: 357 (1963).

17. Kunin, G. M.: The nature of recurrent urinary tract infections in school girls. Proc. 2nd international Congress of Nephrology, Prague, Czechoslovakia, 1964, p. 247 (Excerpta Medica Foundation under the Berne Convention).

18. Kunin, G. M.; Zagha, E. and Paquin, A.J., Jr.: Urinary tract infections in school children. I. Prevalence of bacteriuria and associated urologic findings. New Engl.J. Med. 266: 1287 (1962).

19. MaDonald, R.K.; Mrller, J.H.; Shock, N.W. and MAnchester, B.: Changes in renal hemodynamics associated with intravenous administration of sodium para-aminohippurate. Amer.J. Physiol. 159: 579 (1949).

20. Pryles, C.V.; Wherrett, B.A. and MaCarthy, J. M. : Urinary tract infections in infants and children: Long term prospective study. Amer.J. Dis. Child. 108: 1 (1964).

21. RaAschaU, R.: Studies of chronic pyelonephritis with special reference to the kidney function (Munksgaard, Copenhagen 1948).

22. Rubin, M. I.; Bruck, E. and Rapoport, M.: Maturation of renal function in childhood: Clearance studies. J. clin. Invest. 28: 1144 (1949).

23. Selkurt, E. E.: Effect of ureteral blockade on renal blood flow and urinary concentrating ability. Amer.J. Physiol. 205: 286 (1963).

24. Sмiтh, H.W.: The kidney structure and function in health and disease (Oxford University Press, New York 1951).

25. Smrth, W.W.; Finkelstein, N. and Smith, H.W.: Renal excretion of hexitols (sorbitol, mannitol, and dulcitol) and their derivatives (sorbitan, isoman- 
Alterations in renal cortical blood flow in infants and children with urinary tract infections 345

nice, and sorbide) and of endogenous creatininelike chromogen in dog and man. J. biol. Chem. 135: 231 (1940).

26. TAGgart, J.V.: Some biochemical features of tubular transport mechanisms; in: The kidney (ed. Lewis, A.A.G. and Wolstenholme, G.E.W.) (Little, Brown, Boston, Mass. 1954).

27. West, J.R.; Smith, H.W. and Chasis, H. : Glomerular filtration rate, effective renal blood flow, and maximal tubular excretory capacity in infancy. J.Pediat. 32: 10 (1948).
28. WINBERG, J.: Renal function studies in infants and children with acute nonobstructive urinary tract infections. Acta paediat. 48: 577 (1959).

29. Supported by USPHS Grants HD 0666, HD 01754, HE 5353, and FR 05360.

30. Requests for reprints should be addressed to: Philip L. Calcagno, M.D., Department of Pediatrics, Georgetown University Hospital, 3800 Reservoir Road, N.W., Washington, D.C. 20007 (USA).

\section{A P PENDIX \\ Case Histories}

Patient Age Comments

No.

16 days $\quad$ Negro female with unexplained jaundice associated with bacteriuria $100,000 \mathrm{col} . * / \mathrm{ml}$ $E$. coli. Clearing of urinary findings with antimicrobial therapy. Therapy continued for 4 months. Failure to thrive.

3 months Cinecystogram normal. No ureteral reflux. Urine cultures persistently positive in spite of therapy.

4 months Renal clearances demonstrated a reduced $\mathrm{G}_{\mathrm{PAH}}$. Cystoscopy and cystogram revealed severe bladder neck contracture with reflux up right ureter. Urethral dilatation and sulfisoxazole therapy instituted and continued.

13 months Repeat clearances, cystoscopy and cystogram. Bladder neck contracture and right ureteral reflux persisted. Mild right hydronephrosis. $\mathrm{C}_{\mathrm{PAH}}$ clearances normal $\mathrm{Y}-\mathrm{V}$ plasty repair and right ureteral transplant performed. Discharged on antimicrobial therapy $(\mathrm{S})^{*}$ for 2 months.

Child has been well during the past two years. Urinalysis and cultures continue to be negative.

Conclusion BNC*, reflux and right hydronephrosis. Clearances showed initial lowered $\mathrm{C}_{\mathrm{PAH}}$ values, increasing to normal at 13 months despite presence of pyuria and bacteriuria. Antimicrobial therapy given for 12 months continuously.

\begin{tabular}{|c|c|c|}
\hline 2 & $\begin{array}{l}16 \text { months } \\
25 \text { months } \\
39 \text { months }\end{array}$ & $\begin{array}{l}\text { Negro male. Onset with fever and pyuria, proteinuria and bacteriuria. IVP* : left hydro- } \\
\text { nephrosis with a partial obstruction at right uretero-pelvic junction. Sulfisoxazole therapy } \\
\text { for } 5 \text { months. } \\
\text { Cystoscopy and cystogram revealed meatal stenosis, mild BNC and left ureteral reflux. } \\
\text { Dilatation and circumcision performed. IVP: left hydronephrosis and uretero-pelvic hold } \\
\text { up of contrast media. C.PAH clearances were reduced. Antimicrobial therapy given for } \\
\text { one additional month, followed by no therapy for } 19 \text { months. Urinalysis and cultures } \\
\text { negative. } \\
\text { During this interval, weight gain adequate even without antimicrobial therapy. IVP still } \\
\text { showed mild hydronephrosis on left. Prompt emptying of left uretero-pelvic junction } \\
\text { noted. } \\
\text { Mild BNC, no reflux. C.PAH clearances still reduced. Urine sediment and culture were } \\
\text { negative. } \\
\text { Repeat studies revealed normal } \mathrm{C}_{\mathrm{I}} \text { and } \mathrm{C}_{\mathrm{PAH}} \text {. Mild left hydronephrosis and BNC per- } \\
\text { sisted. Off therapy for total of } 32 \text { months. } \\
\text { Conclusion } \\
\text { BNC, left hydronephrosis, left ureteral reflux, and lowered values for } \mathrm{C}_{\mathrm{PAH}} \\
\text { clearances at } 6 \text { months. Dilatation and circumcision at } 6 \text { months. No anti- } \\
\text { microbial therapy for } 19 \text { months. Repeat studies at } 25 \text { months revealed con- } \\
\text { tinued reduced } \mathrm{C}_{\mathrm{PAH}} \text { clearances with improvement in urologic findings: less } \\
\text { left hydronephrosis, disappearance of left ureteral reflux and less BNC. Pa- } \\
\text { tient asymptomatic for } 18 \text { months; urinalysis and cultures continued to be } \\
\text { negative. Normal clearances at age } 39 \text { months. }\end{array}$ \\
\hline
\end{tabular}

* See page 351 for abbreviations 


\begin{tabular}{lll}
\hline $\begin{array}{l}\text { Patient } \\
\text { No. }\end{array}$ & Age & Comments \\
\hline 3 & 2 months & $\begin{array}{l}\text { Negro male with fever and palpable abdominal mass. Urine sediment showed pyuria, } \\
\text { proteinuria and white blood cell casts. Urine culture } 100,000 \text { col./ml of proteus. IVP: } \\
\text { right hydronephrosis with hydroureter and minimal blunting of the left calyceal system. } \\
\text { Voiding cystogram showed large bladder with posterior urethral valves and marked right } \\
\text { ureteral reflux. Suprapubic cystotomy performed. Antimicrobial therapy (S) administer- } \\
\text { ed for next 4 months. }\end{array}$ \\
3 months & $\begin{array}{l}\text { Persistent fever and urinary tract infections with pseudomonas and aerogenes. } \\
\text { Resection of posterior urethral valves and Y-V plasty repair was performed. Antimicro- } \\
\text { bial therapy (S) continued. } \\
\text { Renal functional clearances were normal. IVP showed decrease in right hydronephrosis } \\
\text { with complete disappearance of left calyceal dilatation. Symptomatology continues with } \\
\text { dribbling on urination and persistent bacteriuria 100,000 col./mI } E \text {. coli. } \\
\text { Conclusion Posterior urethral valves, right hydronephrosis and hydroureter with blunting } \\
\text { left calyceal system. Surgical repair at 4 months. Clearances done two months } \\
\text { later revealing normal values. }\end{array}$ \\
\hline
\end{tabular}

$4 \quad 3 \frac{1}{2}$ weeks Negro male with fever of unknown origin. Urinalysis showed numerous WBC and urine cultures showed over $100,000 \mathrm{col} . / \mathrm{ml}$ of $E$. coli and enterococci. IVP outlined normal renal contours. Antimicrobial therapy (S) was administered for 6 months.

4 months Cystoscopy and cystogram revealed BNC, meatal stenosis with right ureteral reflux. Circumcision and urethral dilatation were performed. Antimicrobial therapy (S) was continued.

6 months Renal functional clearances revealed reduced $\mathrm{C}_{\mathrm{PAH}}$. Cystoscopy and cystogram showed normal urinary outlet, but right ureteral reflux still present. Repeat urinalysis and cultures continue to be negative during the past 2 years.

Conclusion Meatal stenosis, BNC and right ureteral reflux. Following dilatation, circumcision and antimicrobial therapy (S) for 2 months, urologic findings improved yet $\mathrm{C}_{\mathrm{PAH}}$ was reduced.

52 months Negro female found to have pyuria and bacteriuria of $100,000 \mathrm{col} . \mathrm{ml}$ of coliform organisms on routine examination. IVP normal. Cinecystogram: $20-40 \%$ retention post voiding. Antimicrobial therapy (S) for two weeks.

3 months Recurrence of pyuria and bacteriuria 80,000 col. $/ \mathrm{ml}$ coliform. Improvement of bacteri-

8 months Renal functional clearances show lowered values for $\mathrm{C}_{\mathrm{PAH}}$. Urine cultures $100,000 \mathrm{col} . / \mathrm{ml}$ of aerobacter, enterococci and E. coli. Cystoscopy revealed BNG and gaping ureters, but no ureteral reflux. Urethral dilatation performed and antimicrobial therapy $(T) *$ instituted and continued for 4 months.

15 months Repeat functional clearances continued to show reduced $\mathrm{C}_{\mathrm{PAH}}$ value. Cystoscopy and cystogram revealed a normal urinary outlet but demonstrated reflux up the right ureter. Antimicrobial therapy (S) continued for one additional month.

16 months Cystoscopy and cystogram were normal.

Patient was normal during past year. No medications required since last visit. Urinalysis and cultures were negative.

Conclusion Post voiding retention, BNG, gaping ureters, right ureteral reflux, clearing with dilatation and antimicrobial therapy $(S)$. Two sets of clearances done seven months apart reveal reduced $\mathrm{C}_{\mathrm{PAH}}$ values.

62 months Negro female found to have pyuria and bacteriuria $(100,000 \mathrm{col} / \mathrm{ml}$ coliform) in association with malnutrition. Antimicrobial therapy (S) given for 11 days.

13 months Returned to Emergency Room for malnutrition, fever, and urinary tract infection (over $100,000 \mathrm{col} . / \mathrm{ml}$ of coliform). IVP showed normal kidneys and ureters. Post voiding film revealed $25 \%$ retention of contrast media. Cystoscopy was normal. Antimicrobial therapy (S) was given for 6 months. The patient was followed in the renal clinic monthly where she showed adequate weight gain and negative urinalysis and cultures.

19 months Therapy discontinued. During the following 6 months, weight gain was inadequate. Urine cultures continued to be negative.

24 months Renal functional clearances were normal. Urine culture was negative. IVP showed normal upper collecting systems, but with retention of contrast media after two hours. Cystoscopy and cystogram revealed mild BNC. No ureteral reflux noted. Urethra was dilated and patient was given antimicrobial therapy $(S)$ for an additional 5 months.

29 months Repeat renal functional clearances were still normal. Cystoscopy was normal. Urinalysis and cultures were normal. She has continued to be asymptomatic without medications and free of urinary findings during the past year.

Conclusion Mild BNG. Renal functional clearances normal on two occasions. 
Alterations in renal cortical blood flow in infants and children with urinary tract infections 347

\begin{tabular}{|c|c|c|}
\hline $\begin{array}{l}\text { Patient } \\
\text { No. }\end{array}$ & Age & Comments \\
\hline 7 & $2^{11} / 12$ years & $\begin{array}{l}\text { White female with first acute attack of urinary tract infection with symptomatology of } \\
3 \text { weeks duration. Pyuria, proteinuria and bacteriuria } 100,000 \text { col./ml of } E \text {. coli and pro- } \\
\text { teus vulgarus. IVP revealed normal upper collecting tracts. Cystoscopy showed meatal } \\
\text { stenosis with bladder trabeculations. Cystogram did not show any reflux. Renal func- } \\
\text { tional clearances indicated a reduced C.PAH value. Antimicrobial therapy (N) was ad- } \\
\text { ministered in addition to a meatotomy. Child lost to follow-up. } \\
\text { Conclusion Meatal stenosis with bladder trabeculations suggstion of urologic obstruction } \\
\text { at outlet. Three-week history of symptoms. First clinical expression warrant- } \\
\text { ing medical care. Reduced } \mathrm{C}_{\mathrm{PAH}} \text { associated. No follow-up. }\end{array}$ \\
\hline
\end{tabular}

824 months Negro male admitted with pain and burning on urination, fever and dehydration. Pyuria and bacteriuria (100,000 col./ml E.coli) demonstrated. Antimicrobial therapy (S) given for six months. Significant bacteriuria persisted.

28 months Cine IVP revealed right hydronephrosis and hydroureter, reflux up left ureter and right ureterocele.

30 months Clearance performed and revealed normal $\mathrm{C}_{\mathrm{pAH}}$ value. Cystoscopic examination showed presence of posterior urethral valves and bilateral reflux. Following clearance test, posterior urethral valves were removed and right ureter was reimplanted. Urinary tract infection cleared.

Conclusion Two-year-old child with right hydronephrosis and hydroureter and bilateral ureteral reflux. $\mathrm{C}_{\mathrm{PAH}}$ values normal level. Infection difficult to irradicate for 6 months with antimicrobial therapy (S); however, surgical intervention was successful with resultant negative urine cultures and sediment.

$9 \quad 47 / 12$ years Negro male in automobile injury resulting in transection of spinal cord at T5 with paraplegia and neurogenic bladder. Pseudomonas $100,000 \mathrm{col} / \mathrm{ml}$ found repeatedly in urine. Pyuria and proteinuria associated. Antimicrobial therapy $(\mathrm{C}) *$ given intermittently during the ensuing 5 months.

5 years Renal functional clearances showed a reduced $\mathrm{C}_{\mathrm{PAH}}$ value. IVP normal. Gystogram revealed small and trabeculated bladder. The child's ureters were transplanted into a loop of ileum (Bricker Procedure).

Conclusion Neurogenic bladder secondary to cord transection. Urinary tract infection documented. Five months later $\mathrm{C}_{\mathrm{PAH}}$ found significantly depressed.

$10 \quad 4^{11} / 12$ years Negro female with known nephrosis for 20 months which responded well to steroid therapy. Relapse associated with pyuria and bacteriuria: $100,000 \mathrm{col} . / \mathrm{ml}$ coliform and enterococcus. Antimicrobial therapy (S) for 3 months.

$5 \%$ years IVP normal. Antimicrobial therapy (S) continued with good response and complete urine clearing after another month's therapy. Sulfisoxazole continued.

$56 / x_{2}$ years Relapse 100,000 col./ml proteus. Antimicrobial therapy $(\mathrm{N})$ given for 2 months without improvement. Bacteriuria persisted.

$58 / 12$ years Clearances showed borderline normal $\mathrm{C}_{\mathrm{PAH}}$ values. Cine IVP showed blunting of right calyceal system. Cystoscopy and cystogram revealed meatal stenosis, moderate bladder neck contracture. No ureteral reflux. Marked trabeculations of bladder mucosa noted. Light and electron microscopy showed changes consistent with nephrosis and no evidence of pyelonephritis. Urethral dilatation and meatotomy were performed.

Conclusion Child with nephrosis developed urinary tract infection. Urologic examination revealed meatal stenosis and BNC. After 9 months of unsuccessful medically treated urinary tract infection, low borderline values for $\mathrm{C}_{\mathrm{PAH}}$ were obtained.

$1133_{12}^{3}$ years White female seen for urgency and urinary frequency. Pyuria and bacteriuria 100,000 col./mI $E$. coli. Antimicrobial therapy (S) for 3 months with slight improvement.

$34 / 12$ years IVP normal.

$36 \%$ years Cystoscopic examination showed urethral and meatal stenoses which were dilated.

$3^{8} / 12$ years Relapse with symptomatology, pyuria and bacteriuria $100,000 \mathrm{col} . / \mathrm{ml}$ of $E$. coli. Cystoscopy and dilatation with improvement.

4 years Repeat dilatation. Cystoscopy showed BNC and persistent urethral stenosis. Antimicrobial therapy $(S)$ initiated and continued for 6 months.

$46 / 12$ years Relapse with frequency, urgency associated with pyuria and significant bacteriuria 100,000 col./ml E. coli.

48/12 years Renal functional studies showed normal $\mathrm{C}_{\mathrm{PAH}}$ clearances. Cystoscopy following these studies revealed a slight BNC. Cystogram showed normal bladder and no ureteral reflux. Follow-up for one year without medications. No relapses and urine free of WBC and bacteria. 


Patient Age Comments

No.

Conclusion Child with meatal and urethral stenosis associated with $\mathrm{BNC}$ and urinary tract infection for 17 months. Pyuria and bacteriuria associated with two relapses. In between relapses, child never really symptom-free. Renal functional clearances after 17 months showed normal $\mathrm{C}_{\mathrm{PAH}}$ values. Therapy consisted of repeat dilatation and long-term antimicrobial agents.

$4^{6} / 12$ years Negro female with frequency, fever associated with pyuria, proteinuria and significant bacteriuria $100,000 \mathrm{col} . / \mathrm{ml}$ of coliform and paracolon. Antimicrobial therapy (S) for 2 months.

$48 / 12$ years IVP showed double collecting system on left.

5 years Gystoscopic examination did not show any obstruction or reflux.

$5^{1} / 12$ years Relapse of pyuria and significant bacteriuria. Antimicrobial therapy (S) continued for 1 month.

$5^{4} / 12$ years Renal functional clearances showed borderline normal for $\mathrm{C}_{\mathrm{PAH}}$ values. Urine culture negative. Left renal biopsy did not show evidence of acute or chronic infection.

Conclusion Child without urinary obstructive uropathy associated with urinary tract infection. Antimicrobial therapy cleared urinary sediment and culture findings but symptomatology persisted with lesser intensity. Renal function tests done after 10 months. Short-term antimicrobial therapy given on two occasions.

$135 \%$ White female with dysuria, frequency, flank pain, fever associated with pyuria, proteinuria and bacteriuria 100,000 col./ml coliform. Two previous acute episodes documented in the previous two years. Both episodes treated with short-term antimicrobial therapy (S). IVP normal. No ureteral reflux demonstrated with cystogram. On cystoscopic examination, she was found to have BNC. Renal functional clearances showed low $\mathrm{C}_{\mathrm{PAH}}$ clearances.

$14 \quad 5^{11} / 12$ years Negro female with abdominal pain, anorexia associated with pyuria, proteinuria and bacteriuria 100,000 col./ml coliform. Antimicrobial therapy (S) for 3 months with improvement and clearing of urinary sediment and culture.

$62 / 12$ years Four days after therapy stopped, relapse occurred with symptomatology and urinary findings. Antimicrobial therapy $(S)$ continued for one additional month.

$6^{3} / 12$ years IVP revealed normal upper tract. Cystoscopy showed urethral and meatal stenosis with moderate BNC. No reflux demonstrated with cystogram. Dilatation and meatotomy performed.

$6^{11} / 12$ years Renal functional clearance revealed a low borderline normal $\mathrm{C}_{\mathrm{PAH}}$ value. Renal biopsy of right kidney failed to reveal evidence of infection.

Conclusion Child who one year previous to renal clearances showed two documented attacks of urinary tract infection. These were associated with meatal stenosis and BNC. Antimicrobial therapy (S) given for the first 4 months; meatotomy and urethral dilatation done 4 months after initial infection. Symptoms and urinary findings continued. Antimicrobial therapy (S) not given by parents for the following 6 months. Renal function tests show low $\mathrm{C}_{\mathrm{PAH}}$ values one year after onset.

$15 \quad 5$ years

$5^{1} / 12$ years

$5 \%$ years

$5 / 12$ years
Negro female with abdominal pain, fever, pyuria and bacteriuria $100,000 \mathrm{col} . / \mathrm{ml}$ of E. coli. Antimicrobial therapy (S) for two weeks.

IVP revealed dilatation right superior calyceal system.

Relapse with pyuria and bacteriuria $100,000 \mathrm{col} . / \mathrm{ml}$ of enterococci and aerobacter. Antimicrobial therapy $(\mathrm{C})$ for three weeks.

Renal functional clearance showed reduced values for $\mathrm{C}_{\mathrm{Y}}, \mathrm{C}_{\mathrm{PAH}}$ and TmPAH. Cystoscopy and cystogram revealed a marked urethral and meatal stenosis with an edematous bladder neck, bladder mucosal trabeculations and cystitis. Urethral meatotomy done with urethral dilatation. Two monthly follow-up visits revealed normal urinary sediment and cultures.

Conclusion Child with a known 3-month history of urinary tract infection and x-ray evidence of dilatation of right calyceal system, plus obstruction of the lower urinary outlet. Renal clearances reduced. 
Alterations in renal cortical blood flow in infants and children with urinary tract infections 349

\begin{tabular}{|c|c|c|}
\hline $\begin{array}{l}\text { Patient } \\
\text { No. }\end{array}$ & Age & Comments \\
\hline 16 & $\begin{array}{l}48 / 12 \text { years } \\
411 / 12 \text { years } \\
5^{5} / 12 \text { years } \\
5^{8} / 12 \text { years } \\
6 \text { years } \\
\\
6^{6} / 12 \text { years } \\
7^{4} / 12 \text { years } \\
75 / 12 \text { years } \\
7^{11} / 12 \text { years } \\
8^{4} / 12 \text { years }\end{array}$ & $\begin{array}{l}\text { Negro female with gross hematuria associated with pyuria, proteinuria and bacteriuria. } \\
100,000 \text { col./ml coliform. Antimicrobial therapy }(\mathrm{S}) \text { for } 4 \text { weeks with clearing of symp- } \\
\text { toms, urinary sediment and culture. IVP normal. } \\
\text { Relapse with proteinuria, pyuria and bacteriuria } 100,000 \text { col./ml E. coli. Antimicrobial } \\
\text { therapy (S) for } 6 \text { months initiated. } \\
\text { Therapy discontinued. Urinary sediment and cultures negative. } \\
\text { Relapse with pyuria, proteinuria and bacteriuria. } \\
\text { Renal functional clearance showed normal values for } \mathrm{C}_{I}, \mathrm{C}_{\mathrm{PAH}} \text { and TmPAH. Cysto- } \\
\text { scopic examination revealed meatal stenosis; no ureteral reflux noted. Antimicrobial } \\
\text { therapy discontinued by mother after } 3 \text { months. } \\
\text { Dilatation. } \\
\text { Relapse with frequency and enuresis associated with pyuria and significant bacteriuria } \\
100,000 \text { col./ml E. coli. } \\
\text { Dilatation plus antimicrobial therapy (S) for } 5 \text { months. } \\
\text { Pyuria and significant bacteriuria persist. Antimicrobial therapy changed from (S) to } \\
\text { Polycillin. } \\
\text { Repeat renal functional clearances showed reduced } \mathrm{C}_{\text {PAH }} \text { but increase in TmPAH. } \\
\text { Meatal stenosis dilated once again. Urine cultures were negative. } \\
\text { Conclusion Ghild with a known history of urinary tract infection for } 3 \text { years and } 8 \text { months. } \\
\text { No x-ray evidence of uropathy. Urologic finding of urethral and meatal } \\
\text { stenosis treated with repeat dilatations and appropriate antimicrobial thera- } \\
\text { py (long-term). Renal clearance done at } 16 \text { months after onset were normal } \\
\text { but reduced after } 44 \text { months. }\end{array}$ \\
\hline
\end{tabular}

$17 \quad 6^{6} / 2$ years Negro female seen because of a history of three previous urinary tract infections during the previous year. This episode of dysuria and history of weight loss associated with proteinuria, pyruia, hematuria and bacteriuria ( $E$. coli greater than $10,000 \mathrm{col} . / \mathrm{ml}$ ). Antimicrobial therapy (S) given for 10 months with symptomatic improvement and clearing of urinary sediment and urine cultures.

74/12 years Renal functional clearances showed reduced $\mathrm{C}_{\mathrm{PAH}}$ values. Gine IVP showed partial double collecting system on the right side, otherwise urinary tract normal. Gystoscopic examination revealed meatal stenosis and bladder neck contracture with marked bladder trabeculations. No ureteral reflux noted. Antimicrobial therapy (S) given for 6 months.

$710 / 12$ years Bladder neck contracture still present. Bladder trabeculations. Urethra dilated. Antimicrobial therapy $(\mathrm{S})$ continued for another 6 months.

$8^{4} / 12$ years Dilatation. Antimicrobial therapy (S) continued for another 6 months.

$96 / 12$ years Repeat functional clearances showed improvement in the previously low $\mathrm{C}_{\mathrm{PAH}}$ to normal values. Asymptomatic for 14 months.

Conclusion Child with a documented history of repeat urinary tract infection for 4 years. Associated urologic findings were meatal stensosis and BNG with trabeculations. After 22 months of illness, renal functional clearances showed a reduced $\mathrm{C}_{\mathrm{PAH}}$ value. Antimicrobial therapy continued for 18 months. Dilatation of urethra every 6 months. Repeat clearance 26 months later showed normal value for $\mathrm{C}_{\mathrm{PAH}}$.

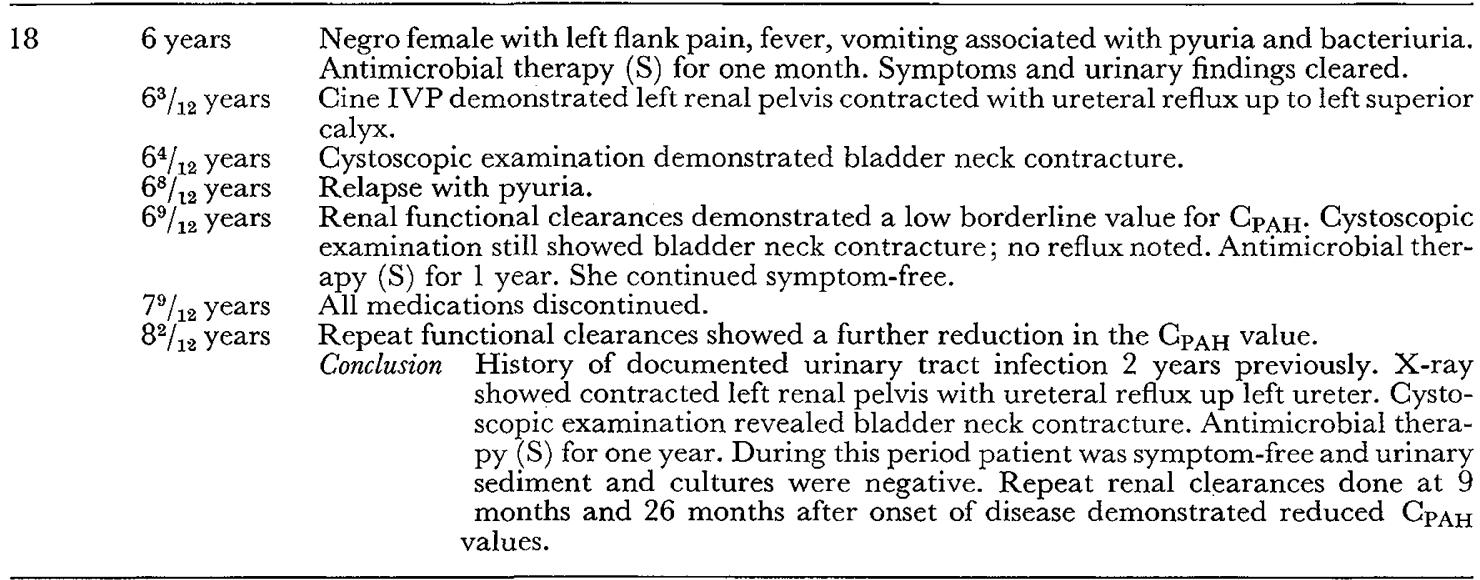

24 Pediat. Res., Vol. 2, No. 5 (1968) 


Patient Age Comments

No.

$19 \quad 5^{\mathbf{1 0}} / 1_{2}$ years Negro female with malnutrition, enuresis, fever associated with pyuria and bacteriuria (E. coli $100,000 \mathrm{col} . / \mathrm{ml})$. IVP normal. Antimicrobial therapy $(S)$ for one month. One relapse after 7 months. Antimicrobial therapy (S) for another 4 months.

$6 \%$ years Renal clearances showed normal $\mathrm{C}_{\mathrm{PAH}}$ values. Cystoscopic examination negative. No ureteral reflux noted.

Conclusion Single documented urinary tract infection 12 months previously. No uropathy demonstrated. Renal clearances normal.

207 years $\quad$ Negro female with frequency of urination, fever, vomiting associated with proteinuria, and pyuria. Urine culture showed $4,000 \mathrm{col} . / \mathrm{ml}$ paracolon. IVP showed right kidney enlarged with blunting superior calyx. Antimicrobial therapy (S) unknown (question as to whether child took medicine).

$7 \% / 12$ years Relapse with fever, enuresis, frequency of urination associated with aerobacter and enterococci, $100,000 \mathrm{col} . / \mathrm{ml}$.

$78 / 12$ years Renal functional clearances showed normal values for $\mathrm{C}_{\mathrm{I}}$, and $\mathrm{C}_{\mathrm{PAH}}$.

Conclusion Urinary tract infection for 8 months. Bladder neck contracture and meatal stenosis found in addition to blunting right superior calyx. Antimicrobial therapy for 8 months. Renal clearances revealed normal values.

$21 \quad 10$ years Negro female with pyuria, and bacteriuria $100,000 \mathrm{col} . / \mathrm{ml} \mathrm{E}$. coli. Cystoscopic examination showed $\mathrm{BNC}$ with bilateral ureteral reflux. Urethra dilated and antimicrobial therapy (S) given for 4 weeks. IVP showed dilatation of right superior calyx.

py $(\mathrm{S})$ given for 4 weeks. IVP showed dilatation
$10^{8} / 12$ years Relapse. Antimicrobial therapy (S) for 4 weeks.

$10^{10} / 12$ years Cystoscopy showed BNC but no ureteral reflux. Dilated.

$10^{10} / 12$ years-

$13 \frac{4}{12}$ years Three relapses all treated with urethral dilatation and antimicrobial therapy (followed by private physician).

$13^{4} / 12$ years Renal functional clearance showed a reduced $\mathrm{C}_{X}$ and low borderline normal $\mathrm{C}_{\mathrm{PAH}}$ values. Cystoscopy showed mild BNC. No reflux. IVP persistence of dilatation and blunting of right superior calyx.

Conclusion Child with history of repeated urinary tract infection associated with bladder neck contracture over a period of $3^{4} / 12$ years. Renal clearance revealed a reduced $\mathrm{C}_{\mathrm{I}}$ and $\mathrm{C}_{\mathrm{PAH}}$ value. No long-term therapy.

$2210^{7} / 12$ years White female found to have asymptomatic pyuria at age 6 . During the next three years several antimicrobial agents were used $(\mathrm{S}),(\mathrm{N})$ with intermittent clearing of pyuria. Cystoscopic examination three times during the period revealed slight bladder neck contracture. Complaint of fatigue became noticeable during the end of her third year of illness.

$13 \%$ years Renal functional clearances revealed normal $\mathrm{C}_{\mathrm{I}}$ and $\mathrm{C}_{\mathrm{PAH}}$ values. Urinary culture demonstrated $30,000 \mathrm{col} . / \mathrm{ml} E$. coli. Cine IVP studies showed normal kidneys and urinary tract. Antimicrobial therapy continued even though urinary sediment and cultures were negative.

$15^{11} / 12$ years Repeat renal functional clearances showed a reduced $\mathrm{C}_{\mathrm{PAH}}$ value. Urine culture and sediment during the performance of these clearances were negative. Renal biopsy showed minimal changes consistent with acute pyelonephritis.

Conclusion Child with asymptomatic pyuria for 3 years. Her only complaint was fatigue. A reduction in $\mathrm{C}_{\mathrm{PAH}}$ value was found on repeat testing $2 \frac{1}{2}$ years after the first clearance studies.

White female with a two-year history of urinary tract infection with pyuria and bacteriuria $100,000 \mathrm{col} . / \mathrm{ml} E$. coli. and treated with several antimicrobial agents $(\mathrm{S}),(\mathrm{C}),(\mathrm{N})$. Renal functional clearances demonstrated reduced $\mathrm{C}_{\mathrm{PAH}}$ values. Cinecystogram showed reflux up right ureter with BNC. Biopsy of kidney showed minimal changes consistent with acute pyelonephritis. Urine culture $40,000 \mathrm{col} . / \mathrm{ml} \mathrm{E}$. coli. Urinary sediment contained WBC and granular casts.

Conclusion Child with a three-year history of urinary tract infection associated with right ureteral reflux and reduced $\mathrm{C}_{\mathrm{PAH}}$ values. 
Alterations in renal cortical blood flow in infants and children with urinary tract infections 351

\begin{tabular}{|c|c|c|}
\hline $\begin{array}{l}\text { Patient } \\
\text { No. }\end{array}$ & Age & Comments \\
\hline 24 & 2 years & $\begin{array}{l}\text { White female with history of two previous undocumented attacks of acute urinary tract } \\
\text { infection with pyuria and proteinuria } 5 \text { and } 6 \text { mos previously. Both episodes treated with } \\
\text { short-term antimicrobial agent }(\mathrm{S}) \text { and dilatation of urethra. Cystoscopic examination } \\
\text { showed BNC. Normal renal function clearances obtained } 6 \text { months after first attack. } \\
\text { Child followed for two years without evidence of urinary tract infection. } \\
\text { Conclusion Child without documented urinary tract infection, i. e. no urine culture } \\
\text { obtained. Clearance data obtained } 5 \text { months after second attack of apparent } \\
\text { urinary tract infection revealed normal values. }\end{array}$ \\
\hline
\end{tabular}

2533 months $\quad$ Negro female child with fever, convulsions, urinary frequency, dysuria and pyuria. Urine culture negative. IVP showed normal upper tracts. Antimicrobial therapy (S) for 9 months. Urinalysis and cultures continued to be normal in spite of complaints of urinary frequency and dysuria.

42 months Clearances performed were in normal range. Cystoscopy and cystogram revealed meatal stenosis and urethritis. No ureteral reflux demonstrated. Meatotomy performed.

Conclusion Symptom primarily of urethritis. Clearances normal. No true obstructive uropathy.

2613 months Negro female with failure to thrive and diarrhea. Urine culture 50,000 paracolon. Pyuria

37 months Readmitted for shigella infection, diarrhea, fever and convulsions. Cystoscopic examination revealed BNC. No ureteral reflux. Urethra was dilated and patient given antimicrobial therapy $(S)$ for 6 months.

43 months Clearances performed showed normal values for $\mathrm{C}_{\mathrm{PAH}}$. IVP normal. Cystoscopy normal. Conclusion Forty-three-month-old female with shigella infection of intestine at age 37 months; no true infection of kidneys documented. On sulfisoxazole 6 months.

$27 \quad 5^{10} / 12$ years Negro female with history of acute glomerulonephritis 2 years previously who was found to have a large bladder, double collecting system on left, bifid right renal pelvis and blunting of the superior calyx. Magacystis syndrome was presumptive diagnosis. Child seen monthly for 4 months for cystoscopy and dilatation of urethra.

$61 \%$ years Renal functional clearances revealed normal values for $\mathrm{C}_{\mathrm{I}}$ and $\mathrm{C}_{\mathrm{PAH}}$.

Conclusion Child with megacystis. No urinary tract infection. Renal clearance values normal.

\begin{tabular}{llllll}
\hline IVP & Intravenous pyelogram & (N) & Nitrofurantoin & Col. & Colonies \\
BNC & Bladder neck contracture & (T) & Tetracycline & & \\
(S) & Sulfisoxazole & (C) & Chloramphenicol & &
\end{tabular}

